AperTO - Archivio Istituzionale Open Access dell'Università di Torino

\title{
On Estimating Achievement Dynamic Models from Repeated Cross Sections
}

\section{This is the author's manuscript}

Original Citation:

Availability:

This version is available http://hdl.handle.net/2318/1528342

since 2016-07-12T12:09:34Z

Published version:

DOI:10.1177/0049124115613773

Terms of use:

Open Access

Anyone can freely access the full text of works made available as "Open Access". Works made available under a Creative Commons license can be used according to the terms and conditions of said license. Use of all other works requires consent of the right holder (author or publisher) if not exempted from copyright protection by the applicable law. 
This is the author's final version of the contribution published as:

Contini, D.; Grand, E.. On Estimating Achievement Dynamic Models from Repeated Cross Sections. SOCIOLOGICAL METHODS \& RESEARCH.

None pp: 1-30.

DOI: $10.1177 / 0049124115613773$

The publisher's version is available at:

http://smr.sagepub.com/cgi/doi/10.1177/0049124115613773

When citing, please refer to the published version.

Link to this full text:

http://hdl.handle.net/2318/1528342 


\title{
On estimating achievement dynamic models from repeated cross-sections
}

\author{
Dalit Contini and Elisa Grand
}

\begin{abstract}
Despite the increasing spread of standardized assessments of student learning, longitudinal data on achievement data are still lacking in many countries. This article raises the following question: Can we exploit cross-sectional assessments held at different schooling stages to evaluate how achievement inequalities related to individual-ascribed characteristics develop over time? This is a highly policy relevant issue, as achievement inequalities may develop in substantially different ways across educational systems. We discuss the issues involved in estimating dynamic models from repeated cross-sectional surveys in this context; consistently with a simple learning accumulation model, we propose an imputed regression strategy that allows to "link" two surveys and deliver consistent estimates of the parameters of interest. We then apply the method to Italian achievement data of fifth and sixth graders and investigate how inequalities develop between primary and lower secondary school.
\end{abstract}

Keywords: achievement inequalities, dynamic models, pseudo-panel estimation, repeated cross sections, standardized assessments 


\section{Introduction}

The expansion of standardized learning assessments at the national and international level has fostered the study of educational inequalities in terms of achievement and acquired competences. International surveys like PISA, TIMSS and PIRLS ${ }^{1}$ have also given the opportunity to highlight remarkable cross-country variability in the extent to which ascribed individual characteristics such as gender and family background affect learning (OECD, 2010a: OECD 2010b; Mullis et al. 2012; Mullis et al. 2012), and to relate these differences to schooling policies and features of the educational systems (eg. Hanushek and Woessmann, 2006; Ammermueller, 2007; Fuchs and Woessmann, 2007; Schuetz et al., 2008).

International assessments and many national studies, however, are cross-sectional. In this context, inequalities can only be investigated at specific grades or children's age. Yet, as emphasized by Cunha et al. (2006), learning processes are cumulative. Thus, greater knowledge of how differentials across socio-demographic groups evolve throughout childhood in different institutional contexts could help the design of effective educational policies to contrast inequalities.

This article raises the following question: in the absence of longitudinal data, can we exploit cross-sectional standardized assessments held at different stages of the schooling career to evaluate how learning inequalities develop over children's life course? This is a highly policy relevant issue, as achievement inequalities may develop in substantially different ways across educational systems.

Since different assessments are often not directly comparable, the existing literature has addressed this issue by computing standardized scores and comparing the average $z$-score of individuals of different backgrounds as children age (Goodman et al., 2009; Jerrim and Choi,

\footnotetext{
${ }^{1}$ PISA (Programme for International Student Assessment) is conducted by OECD. TIMSS (Trends in Mathematics and Science Study) and PIRLS (Progress in International Reading Literacy Study) are promoted by IEA, the International Association for the Evaluation of Educational Achievement. PIRLS evaluates children of grade 4, TIMSS focuses on grades 4 and 8, PISA on children of age 15, regardless of the grade attended.
} 
2013). Widening $z$-scores differentials across socioeconomic backgrounds are interpreted as evidence of increasing inequalities. Yet, this method does not allow distinguishing between direct effects of socio-demographic characteristics operating at each stage of schooling and carryover effects of preexisting gaps. Hence, we need to estimate dynamic models where achievement at a given time point is related to previous achievement and socio-demographic variables.

In the absence of panel data, individuals cannot be traced over time. The econometric literature offers a number of contributions on the estimation of models for panel data from repeated crosssections (Deaton, 1985; Moffitt, 1993; Verbeek and Vella, 2005); as shown by Verbeek and Vella (2005), the conditions for consistent estimation are unrealistic in many contexts.

Drawing from this body of work, we discuss the issues involved in estimating dynamic models from repeated standardized cross-sectional surveys on educational achievement, with the aim to estimate how inequalities across socio-demographic groups develop over stages of schooling. We argue that the model allowing to address this research question is very simple, and therefore the conditions for consistent estimation are met. Coherently with a basic learning accumulation model, we propose an imputed regression strategy that allows to "link" two assessments held at different grades. In essence, true lagged values are substituted with appropriate estimates derived from the first survey. The main drawback of imputed regression, however, is that due to this substitution, standard errors of the estimates are greatly inflated. Imputed regression has a nice property: by explicitly addressing the issue of measurement error, it provides consistent estimates of the parameters of the model of interest even with an additional source of error, i.e. test scores imperfectly measuring achievement.

In the empirical application we exploit the dataset of the Italian learning assessment of reading and math literacy, carried out by the National Evaluation Agency (INVALSI) on $5^{\text {th }}$ and $6^{\text {th }}$ graders in 2010 and 2011 on a sample of more than 30.000 pupils. We investigate gender, socioeconomic, immigrant background and territorial inequalities at the transition between primary and lower 
secondary school. This is a relevant turning point, as secondary school becomes much more demanding in terms of achievement requirements.

Our contribution to the existing literature is threefold. Firstly, we provide a reflection on the advantages of pseudo-panel modelling for the study of the development of learning inequalities as children progress through school, and the conditions for consistent estimation. If repeatedly applied to different segments of the schooling career, this technique allows to investigate how inequalities develop over children's educational life course, moving the focus of the literature on achievement inequalities from a static to a dynamic perspective. Secondly, we substantiate our theoretical arguments with simulations, and show that large samples and good instruments are needed to obtain reliable results. Thirdly, by exploiting a large scale national standardized assessment held at different grades, we analyze how inequalities evolve between primary and lower secondary school in Italy and show that socio-demographic differentials amplify in reading, while the North-South divide severely widens in math.

The paper is organized as follows. In section 2 we define the model. In section 3 we show that the comparison of cross-sectional regression coefficients is not a valid means to study the dynamics of achievement inequalities. In section 4 we present and discuss the imputed regression estimation strategy. Our data and case-study are presented in section 5. Conclusions follow. In the Appendix we present a simulation study designed to evaluate the order of magnitude of standard errors of the estimates obtained with the imputed regression strategy, assess the behavior of alternative estimation strategies and evaluate results in the presence of children repeating grades.

\section{The model}

Consider two cross-sectional surveys assessing students' learning at different stages of the educational career, $t=1$ and $t=2$. A stylized model of learning development and observed performance scores, consistent with the idea of a cumulative process where abilities build up over time, is depicted in Figure 1. Innate ability could be independent of individual characteristics, but 
this condition is not necessary. True unmeasured ability follows a Markov process, as ability at time $t$ depends on ability at time $t-1$, but not on previous ability. Test scores (measured ability) are additive functions of true ability and an independent measurement error. True ability is affected by individual variables such as gender and family background (say, socioeconomic status and immigrant origin).

Children from advantaged backgrounds perform better on average because they usually live in more culturally stimulating environments and receive more parental support, but also because they may attend better schools ${ }^{2}$. School attendance may also be driven by children's ability. We assume that school characteristics at $t=1$ do not directly affect ability at $t=2$, given ability at $t=1 .^{3}$

Figure 1. A stylized dynamic model of cognitive skill

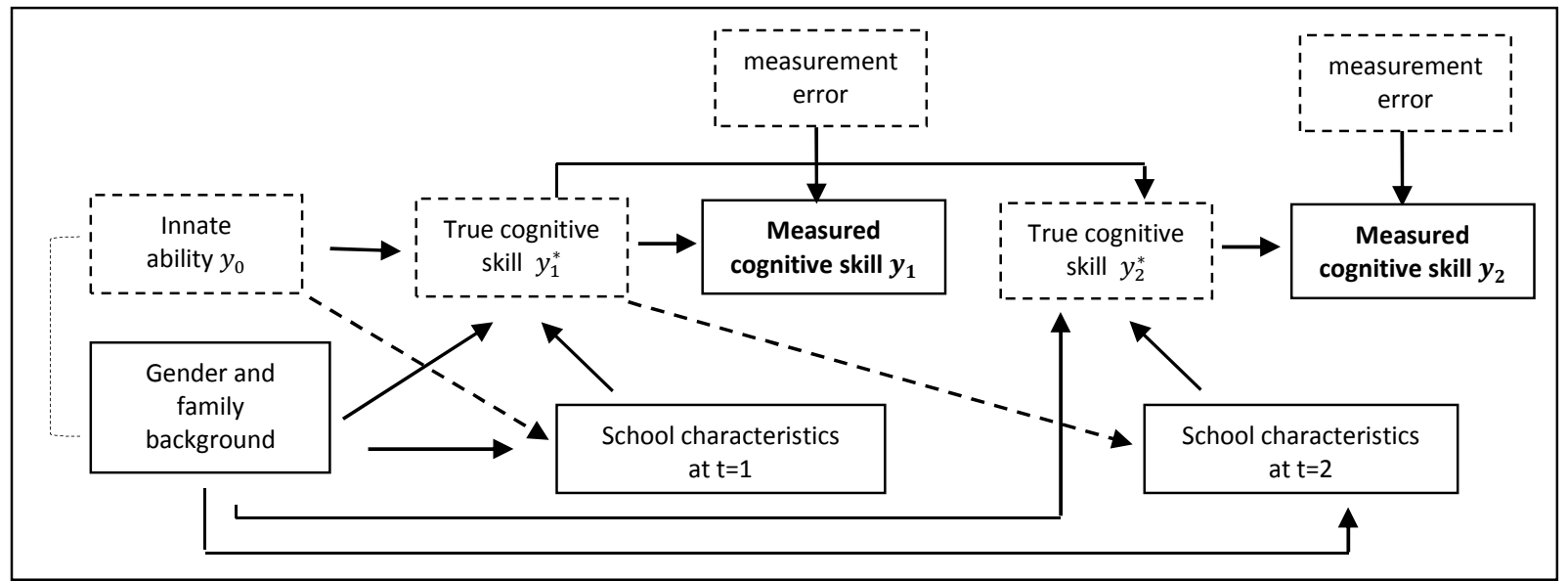

NOTE. Solid boxes represent observable variables, dashed boxes unobservables. Solid arrows represent wellestablished causal relations. Dashed arrows stand for causal relations which might exist or not (depending for example on the educational system). Curved dashed lines represent possible correlations between variables.

\footnotetext{
${ }^{2}$ School enrollment rules vary across countries. In some countries, children are required to enroll into the school of residence; here neighborhoods generally differ with respect to residents' socio-economic and ethnic background. In other countries, there is freedom of choice; due to information asymmetries, children of advantaged backgrounds are likely to select higher quality institutions or schools with better peers. In Italy, in primary and lower secondary school children normally attend the public school of residence, but they may also apply to a different public or private institution. Evidence that that more experienced teachers are more likely to choose schools attended by students of more advantaged family backgrounds is found by Barbieri et al. (2010).

${ }^{3}$ This model applies at the transition between educational levels (for example, between primary and lower secondary), where children change schools between $t=1$ and $t=2$. A simpler picture is obtained if children remain in the same school.
} 
In the above framework, let us consider the following underlying linear autoregressive model:

$$
y_{i t}=\mu_{t}+\gamma_{t} y_{i t-1}+\beta_{t} x_{i}+\varepsilon_{i t}
$$

where $y_{t}$ and $y_{t-1}$ represent performance scores at two moments of the schooling career, and $x$ is a vector of all relevant socio-demographic individual variables. School characteristics are not included among the explanatory variables, the reason being that our interest rests on inequalities, i.e. on the total effect of socio-demographic variables, given by direct effects and indirect effects through school features. If children from advantaged backgrounds attend better schools, adding school variables would capture part of the desired effect. Similarly, we deliberately exclude other intervening variables such as intentions, aspirations, learning strategies, behaviors. Therefore, the set of explanatory variables of interest consists of (nearly) time-invariant socio-demographic characteristics. The error term is independent of explanatory variables and of the lagged score, and independent over time. Moreover, to simplify the exposition, we assume that it is independent across individuals; this assumption will be relaxed in section 4.3.

We consider time-varying parameters, firstly because assessments administered at different grades are not necessarily separated by a uniform time span; more importantly, because there is no reason to assume that the relation between scores of subsequent assessments and the effect of explanatory variables are constant over the schooling career. Indeed, our aim is to study how inequalities develop over time.

The fact that parameters are allowed to change over time implies that (unless we make strong assumptions on how they evolve) we must consider two assessments at a time, and estimate the model for each pair of subsequent assessments. Considering a scalar explanatory variable to simplify the exposition, with two waves, the general model (1) reduces to:

$$
\begin{aligned}
& y_{i 1}=\mu_{1}+\rho x_{i}+\varepsilon_{i 1} \\
& y_{i 2}=\mu_{2}+\gamma y_{i 1}+\beta x_{i}+\varepsilon_{i 2}
\end{aligned}
$$

The error terms include a random component with the usual properties and measurement error, 
assumed independent of true scores. $\varepsilon_{1}$ also captures innate ability; $\varepsilon_{2}$ is an independent random component operating on top of the effect of individual characteristics and previous achievement. ${ }^{4}$ $\rho$ and $\beta$ are measures of learning inequality. The parameter of main interest is $\beta$, representing differentials developing between times $t=1$ and $t=2$, on top of those already in place at $t=1 .{ }^{5}$ If $\rho \neq 0$ and $\beta=0$ the explanatory variable affects achievement up to $t=1$, but given achievement at $t=1$, on average at $t=2$ children of different backgrounds reach the same performance level. On the other hand, if $\rho$ and $\beta$ have the same sign inequalities widen; if they have opposite signs, they weaken or change direction.

Notice that we do not assume a conventional static model for panel data with individual fixed effects such as $y_{i t}=\mu_{t}+\alpha_{i}+\beta_{t} x_{i}+\varepsilon_{i t}$, because the autoregressive model is theoretically better suited to represent a cumulative learning process where competencies build up over time. In addition, at $t=2$ this model is a particular case of (3) with $\gamma=1$. We do not consider a dynamic model with fixed-effects either, firstly because with two points in time the model would be unidentified, secondly because the fixed effect component is redundant if we conceive it as innate ability (the assumed Markov structure posits that ability at $t=2$ does not depend on innate ability given ability at $t=1)$.

\subsection{An alternative derivation of the model}

In the previous section we specified the panel data model as conventionally done in econometrics. We now derive the model from the perspective of individual growth models. ${ }^{6}$ Consider first a set of cross sectional assessments using a unique scale to measure achievement as children age, i.e. scores are "vertically equated". ${ }^{7}$ In this case subsequent scores follow the relation: $y_{i 2}=y_{i 1}+\delta_{i}$,

\footnotetext{
${ }^{4}$ According to (1), $y_{i, t-1}=\mu_{1}+\gamma_{t-1} y_{i, t-2}+\beta_{t-1} x_{i}+\varepsilon_{i, t-1}$. Going backwards and making repeated substitutions, $y_{t-1}$ can be expressed as a function of innate ability $y_{0}$ that, being unobservable, enters the error term. Hence, the resulting equation (2) should be intended as a reduced form model for $y_{1}$.

${ }^{5} \beta$ correctly identifies the total effect of $x$ on $y_{t}$, given by the sum of direct effects and indirect effects through school characteristics at $t=2$. This can be easily demonstrated analytically, and by means of simulations (see Appendix A).

${ }^{6}$ Growth models analyze an outcome variable measured at repeated occasions and model it as a function of time (Singer, Willett, 2003). They are often used in the statistic-educational literature for accountability purposes, to evaluate school effectiveness and assess the impact of specific educational programs.

7 To create a vertical scale, scores from two tests are linked statistically through a process known as calibration, so
} 
where $\delta_{i}$ is achievement growth. If growth is individual-specific and depends on explanatory variables and previous achievement, $\delta_{i}=\Delta+\beta x_{i}+\theta y_{i 1}+\varepsilon_{i 2}$ and thus $y_{i 2}=\Delta+(1+$ $\theta) y_{i 1}+\beta x_{i}+\varepsilon_{i 2}$

On the contrary, if achievement scores are not equated, the relation between subsequent scores would be: $y_{i 2}=\tilde{y}_{i 1}+\delta_{i}$, where $\tilde{y}_{i 1}=\varphi+\omega y_{i 1}$ represents achievement at $t=1$ in the measurement scale employed at $t=2$. Since $\varphi$ and $\omega$ are not known and not identifiable, we cannot measure absolute growth, but only evaluate individuals' position relative to each other. In the general case, the model then becomes:

$$
y_{i 2}=\varphi(1+\theta)+\Delta+\omega(1+\theta) y_{i 1}+\beta x_{i}+\varepsilon_{i 2}
$$

The resulting model has the structure of (3), with $\gamma=\omega(1+\theta)$. Hence, $\gamma$ does not describe the dynamics of the learning process, as it depends on a rescaling factor that allows to translate scores at $t=1$ into scores at $t=2$. Moreover, since $\theta$ is unidentified, without vertically equated scores we cannot test whether the achievement of well performing children grows more (or less) than that of lower performing ones. ${ }^{8}$

\section{Cross-sectional strategies: comparison of regression coefficients}

Model (2) can be estimated with conventional methods using the cross-sectional survey at $t=1 .^{9}$ Can $\beta$ in model (3) be consistently estimated with a simple fully cross-sectional strategy - the comparison of achievement gaps between children of different backgrounds (or the corresponding regression coefficients) as children progress through school? ${ }^{10}$

\footnotetext{
that scores can be expressed on a common scale. TIMSS provides horizontally equated scores (scores of surveys of a given grade at different occasions are equated), but does not equate scores of assessments of different grades. The Italian survey employed in our empirical analysis does not equate scores, neither horizontally, nor vertically.

${ }^{8}$ Due to the issue of "regression to the mean", in the presence of measurement error in test scores the effect of previous performance would be difficult to identify even with equated scores (Jerrim and Vignoles, 2013). Ceiling effects may also operate (Betebenner and Linn, 2010).

${ }^{9}$ If innate ability is independent of $x, \hat{\rho}$ captures the effects of family background related to environmental and cultural factors. If, as maintained by some scholars, the assumption is not valid, $\hat{\rho}$ will also capture genetic effects. Note that this issue is not relevant for the estimation of (3), as in this case innate ability is entirely captured by $y_{1}$.

${ }^{10}$ The arguments traced in this section are detailed in a recent paper by the authors.
} 
Consider the expression:

$$
\left(E\left[y_{2} \mid x+1\right]-E\left[y_{2} \mid x\right]\right)-\left(E\left[y_{1} \mid x+1\right]-E\left[y_{1} \mid x\right]\right)
$$

In the general case, this quantity can be decomposed as:

$$
\beta+\omega \theta\left(E\left[y_{1} \mid x+1\right]-E\left[y_{1} \mid x\right]\right)+(\omega-1)\left(E\left[y_{1} \mid x+1\right]-E\left[y_{1} \mid x\right]\right)
$$

Hence, the above differential equals $\beta$ only in the simplest situation, where scores are vertically equated $(\omega=1)$ and growth does not depend on previous achievement $(\theta=0)$. It is worth noticing that the first two terms of (5) represent the overall achievement growth differential: ${ }^{11}$

$$
\left(E\left[y_{2} \mid x+1\right]-E\left[\tilde{y}_{1} \mid x+1\right]\right)-\left(E\left[y_{2} \mid x\right]-E\left[\tilde{y}_{1} \mid x\right]\right)
$$

$\beta$ is the differential developed between the two assessments that can be directly ascribed to $x$, while $\omega \theta\left(E\left[y_{1} \mid x+1\right]-E\left[y_{1} \mid x\right]\right)$ captures the effect driven by the preexisting achievement gap. The last term of (5), instead, has no substantive meaning. Therefore, the cross-sectional regression coefficient differential on absolute scores does not convey useful information on the development of inequalities, as it fails to identify $\beta$ - which accounts for new inequalities developed between $t=1$ and $t=2-$ but also the overall achievement growth differential - which incorporates carryover effects of preexisting gaps.

\subsection{Regression coefficient difference on standardized scores}

The main strategy adopted in the existing literature to overcome the difficulties in comparing test scores of different assessments is to standardize scores and compare the average $z$-scores of individuals of different backgrounds as children age (Goodman et al., 2009; Jerrim and Choi, 2013). ${ }^{12}$ Results are typically illustrated by simple graphs: widening $z$-scores differentials across socioeconomic backgrounds are interpreted as evidence of increasing inequalities.

\footnotetext{
${ }^{11}\left(E\left[y_{2} \mid x+1\right]-E\left[\tilde{y}_{1} \mid x+1\right]\right)-\left(E\left[y_{2} \mid x\right]-E\left[\tilde{y}_{1} \mid x\right]\right)=\left(E\left[y_{2} \mid x+1\right]-E\left[y_{2} \mid x\right]\right)-\left(E\left[\tilde{y}_{1} \mid x+1\right]-E\left[\tilde{y}_{1} \mid x\right]\right)=$ $\beta+(1+\theta)\left(E\left[\tilde{y}_{1} \mid x+1\right]-E\left[\tilde{y}_{1} \mid x\right]\right)-\left(E\left[\tilde{y}_{1} \mid x+1\right]-E\left[\tilde{y}_{1} \mid x\right]\right)=\beta+\omega \theta\left(E\left[y_{1} \mid x+1\right]-E\left[y_{1} \mid x\right]\right)$.

${ }^{12}$ Note that applying regression coefficients difference on international scores is not equivalent to applying regression coefficients difference on standardized scores. International assessments PIRLS, PISA and TIMSS do provide standardized scores (with mean 500 and st.dev. 100), but the standardization is performed with reference to a set of countries, varying over time and across surveys.
} 
Indeed, standardized scores are invariant to the metric employed to measure achievement. However with this strategy the sources of change remain unclear. Take standardized scores $z_{1 i}=$ $\frac{y_{1 i}-\bar{y}_{1}}{\sigma_{y 1}}$ and $z_{2 i}=\frac{y_{2 i}-\bar{y}_{2}}{\sigma_{y 2}}$. According to (2) and (3), and considering $x$ as a random variable:

$$
\begin{aligned}
& E\left(z_{1} \mid x+1\right)-E\left(z_{1} \mid x\right)=\frac{\rho}{\sigma_{y_{1}}}=\frac{\rho}{\sqrt{\rho^{2} \sigma_{x}^{2}+\sigma_{\varepsilon_{1}}^{2}}} \\
& E\left(z_{2} \mid x+1\right)-E\left(z_{2} \mid x\right)=\frac{\gamma \rho+\beta}{\sigma_{y_{2}}}=\frac{\gamma \rho+\beta}{\sqrt{(\gamma \rho+\beta)^{2} \sigma_{x}^{2}+\gamma^{2} \sigma_{\varepsilon_{1}}^{2}+\sigma_{\varepsilon_{2}}^{2}}}
\end{aligned}
$$

In the simplest case, with no direct effects of the explanatory variables $(\beta=0)$, no carryover effects of previous inequalities $(\theta=0)$, and the same metric used at $t=1$ and $t=2(\omega=1)$ :

$$
\left[E\left(z_{2} \mid x+1\right)-E\left(z_{2} \mid x\right)\right]-\left[E\left(z_{1} \mid x+1\right)-E\left(z_{1} \mid x\right)\right]=\frac{\rho}{\sqrt{\rho^{2} \sigma_{x}^{2}+\sigma_{\varepsilon_{1}}^{2}+\sigma_{\varepsilon_{2}}^{2}}}-\frac{\rho}{\sqrt{\rho^{2} \sigma_{x}^{2}+\sigma_{\varepsilon_{1}}^{2}}}<0
$$

Here the average distance between children of different backgrounds narrows, simply because at $t=2$ there is higher (unexplained) variability. Yet, we could observe the same result if, given previous scores, children of disadvantaged backgrounds perform better $(\beta<0)$ or if achievement growth is negatively related to performance at $t=1(\theta<0)$.

Summing up, strategies based on the comparison of regression coefficients on cross-sectional data do not allow distinguishing between the relevant sources of the observed changes in the position of groups of pupils relative to each other. To do so we need to estimate the dynamic model (3) directly.

\section{Estimation of the dynamic model}

The problem we address here is how to estimate (3) in the absence of genuine longitudinal data, where the data derive from independent cross-sectional surveys held at different stages of schooling, each being a random sample of the same underlying population of children. 
Consider individuals interviewed at $t=2(\mathrm{CS} 2)$ : even if their own lagged scores $y_{1}$ are unobserved, we can obtain $y_{1}$ for different but "similar" children - i.e. sharing the same observed characteristics - by exploiting individuals interviewed at $t=1$ (CS1). A simple strategy would be to randomly select for each child in CS2 a similar child in CS1, and use her score $y_{1}^{\prime}$ instead of true $y_{1}$. This strategy, however, leads to severely biased results, because the lagged score is affected by (large) measurement error. Conventional methods to correct for measurement error (Fuller, Hidiroglou; 1978) are not appropriate here, because they assume the CEV (classical error in variables) condition, i.e. that measurement error is independent of true values. In this case, however, the error is related to both true and observed values. In fact, if $y_{i 1}=\mu_{i}+u_{i 1}$ and $y_{i 1}^{\prime}=$ $\mu_{i}+u_{i 1}^{\prime}$ (where $\mu_{i}$ is the mean score of an individual with given $x$ ), measurement error is $y_{i 1}-$ $y^{\prime}{ }_{i 1}=u_{i 1}-u_{i 1}^{\prime}$

An alternative strategy could be the estimation of a regression model for cell means, where cells are defined as groups of similar individuals. In this case, instead of matching individuals from different cross-sections, we match cells, i.e. groups of children sharing the same characteristics. ${ }^{13}$ The main advantage of this strategy over individual matching is that measurement error of group means is smaller. If the number of cells is fixed, the sampling variance of the cell means tend to zero as the overall sample size expands. Hence, OLS estimates are consistent. In any particular sample, however, the presence of measurement error in $y_{1}$ will lead to biased estimates. When applying (2) and (3) to cell means, we obtain:

$$
\begin{aligned}
& \bar{y}_{c 1}=\mu_{1}+\rho x_{c}+\bar{\varepsilon}_{c 1} \\
& \bar{y}_{c 2}=\mu_{2}+\gamma \bar{y}_{c 1}+\beta x_{c}+\bar{\varepsilon}_{c 2}
\end{aligned}
$$

Yet, since the model for achievement at $t=1$ is estimated from CS1 instead of CS2, what we actually estimate is:

\footnotetext{
${ }^{13}$ Cell mean regression has been applied in a variety of contexts to analyze repeated cross-sectional data. Card and Lemieux (1996), for example, use it to analyze changes in returns to skill and wage inequalities.
} 


$$
\bar{y}_{c 2}=\mu_{2}+\gamma \bar{y}_{c 1}^{\prime}+\beta x_{c}+\gamma\left(\bar{y}_{c 1}-\bar{y}_{c 1}^{\prime}\right)+\bar{\varepsilon}_{c 2}
$$

where $\bar{y}_{c 1}^{\prime}$ is the mean value of $y_{1}$ in cell $c$ in CS1. Since measurement error $\bar{y}_{c 1}-\bar{y}_{c 1}^{\prime}$ is correlated with $\bar{y}_{c 1}^{\prime}$, OLS estimates are biased. Again, since the error is not CEV, the method proposed by Fuller, Hidiroglou (1978) does not solve the problem. ${ }^{14}$

Note also that if the explanatory variables are the same at $t=1$ and $t=2$, the model for $t=2$ is unidentified because $y_{1}$ cell means are a linear function of $x$. Therefore, as we will also argue for the imputed regression technique described below, we need to find a variable affecting $y_{1}$ but not $y_{2}$, and define cells by taking this auxiliary variable into account.

\subsection{Imputed regression}

The conditions for identification and consistent estimation of general linear dynamic panel data models with repeated cross-sections are discussed in Moffitt (1993) and later developed by Verbeek, Vella (2005). The basic idea is that the lagged dependent variable can be replaced by a predicted value from an auxiliary regression using individuals observed in previous cross-sections: the resulting measurement error will generally be uncorrelated with estimated lagged performance and therefore will not lead to inconsistent estimates, as is the case with CEV errors. Measurement error, however, must be uncorrelated also with all other explanatory variables. Whether these conditions are met depends crucially on the nature of the dynamic model and of the model employed to predict lagged values. Verbeek and Vella (2005) argue that these requirements are unrealistic in many contexts; they show, however, that they hold if there are no time-varying exogenous variables or the time-varying exogenous variables are not auto-correlated. Our context is particularly simple: in first place, because the only source of dynamics in the process is the autoregressive component, while individual fixed effects are not included; secondly, because the explanatory variables of interest are all time-invariant socio-demographic characteristics.

\footnotetext{
${ }^{14}$ As shown in a simulation exercise in Appendix A (Table A3).
} 
Yet, if the set of independent variables is identical for $y_{1}$ and $y_{2}-$ a likely occurrence when we focus on performance differentials across ascribed individual characteristics - model (3) is unidentified when substituting $y_{1}$ with $\hat{y}_{1}$. Hence, in order to bypass collinearity, we must find a variable $w$ affecting performance at $t=1$ but not directly related to later performance.

Assuming the following model for $y_{1}$ :

$$
y_{i 1}=\mu_{1}+\rho x_{i}+\delta w_{i}+\varepsilon_{1 i}
$$

we substitute $y_{1}$ with its OLS estimate $\hat{y}_{1}^{\prime}$ derived from CS1. Expressed in terms of $\hat{y}_{1}^{\prime}$, model (3) becomes:

$$
y_{i 2}=\mu_{2}+\gamma \hat{y}_{i 1}^{\prime}+\beta x_{i}+\left[\gamma\left(y_{i 1}-\hat{y}_{i 1}^{\prime}\right)+\varepsilon_{2 i}\right]
$$

Since in large samples $\hat{y}_{1}^{\prime}$ and $\hat{y}_{1}$ (the estimate that would be derived from CS2 if longitudinal data were available) are nearly coincident, the estimation of (7) is basically equivalent to the estimation of $y_{i 2}=\mu+\gamma \hat{y}_{i 1}+\beta x_{i}+\left[\gamma\left(y_{i 1}-\hat{y}_{i 1}\right)+\varepsilon_{i 2}\right]$. As seen above, measurement error derived from using $\hat{y}_{1}$ instead of true $y_{1}$ is not CEV: however, for OLS properties $\left(y_{1}-\hat{y}_{1}\right)$ is uncorrelated with $\hat{y}_{1}$. Thus, OLS estimates of (7) are consistent. ${ }^{15}$ However, the resulting standard errors are larger than with longitudinal data. In Appendix A we describe a simulation study designed to evaluate the bias associated with the matching strategies outlined above and to provide an order of magnitude of the standard errors obtained with imputed regression. As for the latter, the main result is that standard errors are largely inflated, and their magnitude strongly depends on sample size and on the predictive power of the instrument $w{ }^{16}$

Another notable feature of the imputed regression strategy is that by explicitly addressing the measurement error issue, it provides consistent estimates also if test scores are imperfect measures

\footnotetext{
${ }^{15}$ In principle, using $\hat{y}_{1}^{\prime}$ instead of $\hat{y}_{1}$ (i.e. the OLS estimate derived from an independent sample) does induce a small correlation between the error term and explanatory variables. Let us further inspect (7): $y_{i 2}=\mu+\gamma \hat{y}_{i 1}^{\prime}+\beta x_{i}+$ $\gamma\left(\left(y_{i 1}-\hat{y}_{i 1}\right)+\left(\hat{y}_{i 1}-\hat{y}_{i 1}^{\prime}\right)\right)+\varepsilon_{2 i}$. The term $\left(\hat{y}_{i 1}-\hat{y}_{i 1}^{\prime}\right)$ is not independent of $x$ and $\hat{y}_{i 1}^{\prime}$; however, with reasonable sample size it accounts for a negligible share of the total error term. As shown in the simulation study in Appendix A, this caveat has no relevant practical implications.

${ }^{16}$ If $x$ explains a large portion of the variance of $y_{1}$ while $w$ does not, residuals might be small, but $\hat{y}_{1}$ and $x$ will be nearly collinear and the resulting standard errors of the estimates large.
} 
of achievement. Let observed scores $y_{t}=y_{t}^{*}+v_{t}$, with true scores $y_{t}^{*}$ independent of measurement error $v_{t}$. The estimation of equation (2) poses no problems, as measurement error affects the dependent variable. As for model (3), consider the equation for true scores: $y_{i 2}^{*}=\mu_{2}+$ $\gamma y_{i 1}^{*}+\beta x_{i}+\varepsilon_{i 2}^{*}$. The equation for observed scores when the predicted value of $y_{1}$ is introduced is $y_{i 2}=\mu_{2}+\gamma \hat{y}_{i 1}+\beta x_{i}+\varepsilon_{i 2}^{*}+v_{i 2}+\gamma\left(y_{i 1}^{*}-\hat{y}_{i 1}\right)$. The composite error term is independent of all explanatory variables: in particular, $\left(y_{1}^{*}-\hat{y}_{1}\right)$ is independent of $\hat{y}_{1}$ because the regression coefficients of (2) are unbiased in spite of measurement error. Thus, aside from the effect of sampling variability, predicted lagged values are the same if estimated on true or observed scores.

\subsection{Choice of the variables allowing identification}

Our main aim is to estimate consistently model (3). We may therefore use equation (2) to predict $y_{1}$ as precisely as possible, regardless of the nature of explanatory variables. In this perspective, however, two conditions are necessary:

(i) Additional predictors $w$ cannot be relevant variables for achievement at $t=2$.

In other words, they must be valid instruments. For example, assume there are two or more indicators of family background, each capturing different features that affect learning throughout schooling life. If in the attempt to avoid collinearity we exclude either one from the model for $y_{2}$, we get biased estimates, because the omitted variable, entering the error term in equation (7), is correlated with $\hat{y}_{1}$.

(ii) Additional predictors $w$ must be observed at both cross-sections CS1 and CS2

since $\hat{y}_{1}$ is introduced in the model for $y_{2}$ for given $x$ and $w$. As a consequence, natural candidates such as school characteristics at $t=1-$ which could be good instruments as they are liable to affect current but not future performance - cannot be employed, because school features at $t=1$ are usually not recorded in CS2.

It is therefore difficult to find an appropriate instrument. In our empirical analysis we will use the month of birth, as there is widespread evidence that in a given grade younger children perform 
more poorly than their older peers (eg. Lawlor et al. 2006; Crowford et al., 2013), while later achievement should not depend on age given previous achievement.

\subsection{Accounting for the hierarchical structure of the data}

Up until now, we have made the simplifying assumption that all observations are independent. However, this assumption may be questionable, as children in the same school or class are exposed to similar conditions - same environment and school principal, and for children in the same class, same teachers. Hence, observations are independent across groups, but not necessarily within groups. In this section, we examine how pseudo-panel estimation behaves if school/class effects are operating.

Firstly, we consider the inclusion of unobserved school (or class) effects uncorrelated to explanatory variables; secondly, we consider the inclusion of school-level explanatory variables. While the first extension is not problematic, the second may lead to biased estimates of all regression coefficients. Our conclusion - corroborated by a simulation study described in Appendix A - is that the pseudo-panel strategy is not invalidated by hierarchical data, but cannot fully exploit the potential of multilevel modeling (see Goldstein 2010 for an extensive account), that recognize the nested structure of the data and allow for explanatory variables and error components related to units at different levels.

\subsubsection{Unobserved school-effects}

We now relax the assumption of independent observations by considering achievement models with unobserved school effects. Consider the following models for test scores at $t=1$ and $t=2$ :

$$
\begin{aligned}
& y_{i s 1}=\mu_{1}+\rho x_{i s}+\delta w_{i s}+\mu_{s 1}+\varepsilon_{i s 1} . \\
& y_{i s 2}=\mu_{2}+\gamma y_{i 1}+\beta x_{i s}+\mu_{s 2}+\varepsilon_{i s 2} .
\end{aligned}
$$

where $\mu_{s 1}$ and $\mu_{s 2}$ are school-specific random effects at the two occasions. Under the assumptions that unobserved effects at different levels are normally distributed and independent of included explanatory variables, OLS estimates of regression coefficients (ignoring the school-level error 
component) coincide with ML estimates (accounting for the different sources of variance). However, the OLS estimates generally underrate standard errors of the estimates, while ML evaluates them correctly.

With imputed regression, we substitute $y_{1}$ with its estimate $\hat{y}_{1}^{\prime}$ derived from CS1. Expressed in terms of $\hat{y}_{1}^{\prime}$ model (9) becomes:

$$
y_{i c 2}=\mu_{2}+\gamma \hat{y}_{i 1}^{\prime}+\beta x_{i c}+\left[\mu_{c 2}+\gamma\left(y_{i 1}-\hat{y}_{i 1}^{\prime}\right)+\varepsilon_{i c 2}\right]
$$

Since OLS and ML estimates of $\hat{y}_{1}^{\prime}$ coincide, the existence of class effects in the model at $t=1$ does not affect pseudo-panel estimation. Not even the unobserved class effect $\mu_{s 2}$ invalidates the strategy, because it is independent of $x$ and $\hat{y}_{1}^{\prime}$. Yet, to evaluate correctly the standard error of the estimates we should acknowledge the correlation structure of the data in the estimation.

\subsubsection{School-level explanatory variables}

With genuine longitudinal data, a variety of challenging questions involving the effect of potentially endogenous variables such as school characteristics can be addressed using valueadded models. Could we do so with pseudo-panel modeling? Unfortunately, the general answer is no. Consider the following model, where $s_{2}$ are observed school characteristics at $t=2$ :

$$
y_{i 2}=\mu_{2}+\gamma y_{i 1}+\beta x_{i}+\pi s_{i 2}+\varepsilon_{i 2}
$$

If we substitute $y_{1}$ with its estimate $\hat{y}_{i 1}=\hat{\mu}_{1}+\hat{\rho} x_{i}+\hat{\delta} w_{i}$ from CS1, we obtain:

$$
y_{i 2}=\mu_{2}+\gamma \hat{y}_{i 1}+\beta x_{i}+\pi s_{i 2}+\left(\gamma\left(y_{i 1}-\hat{y}_{i 1}\right)+\varepsilon_{i 2}\right)
$$

The problem is that school features at $t=2$ are typically not independent of $\left(y_{1}-\hat{y}_{1}\right)$, as higher ability children are more likely to choose "better" schools. This establishes a correlation between $s_{2}$ and the error term, yielding biased estimates of all regression coefficients (see Table A.5 in Appendix A). ${ }^{17}$ To obtain consistent estimates of (11) we need to estimate $E\left(y_{1} \mid x, w, s_{2}\right)$

\footnotetext{
${ }^{17}$ In most European countries between age 10 and 16 children are tracked into academic and vocational programs, usually offered by distinct institutions. The endogeneity problem described above would be particularly severe if the first assessment was held before tracking and the second one after, because track choice is strongly related to ability.
} 
consistently, but to do so we would need a crystal ball allowing to observe at $t=1$ the characteristics of schools at $t=2 .^{18}$

As emphasized above, the aim of this paper is to analyze the development of learning inequalities over consecutive stages of the educational career, so the relevant explanatory variables are time-invariant socio-demographic factors, and the effect of interest is their total effect on achievement, composed by direct effects and indirect effects via school features. In this perspective, as already argued, it is appropriate not to include school features in the model, because if children from advantaged backgrounds attend better schools, adding school variables would capture part of the desired effect. As shown in the simulation study in the appendix, by excluding the school-specific explanatory variables, we ultimately obtain unbiased estimates of the total effect of socio-demographic factors operating between $t=1$ and $t=2$.

\section{Inequalities in Italy at the turning point between primary and lower secondary school}

\subsection{Italian schooling system and data}

In the Italian educational system, children enter school at age 6 and follow an eight-year period of comprehensive schooling: primary education, lasting five years, and lower secondary education, lasting three years. Lower secondary school ends with a nationally based examination, after which students choose between a variety of upper secondary educational programs, broadly classified into academic, technical and vocational tracks. Despite the absence of performance-related admission restrictions, the academic track is much more demanding than the other tracks.

The study of inequalities at the transition between primary and lower secondary school is of particular interest because the emphasis on achievement requirements greatly increases, as lower secondary school is perceived as the period in which children get prepared for upper secondary

\footnotetext{
${ }^{18}$ The same argument applies to the investigation of the effects of children's behavior at $t=2$ (e.g. effort, time for homework), as behavior at $t=2$ is likely to be dependent on achievement at $t=1$.
} 
education. A similar research question is addressed in De Simone (2013), who focuses on the time-span between grade 4 and 8 with TIMSS. ${ }^{19}$

We use the repeated cross-sectional data of the standardized learning assessment administered by the Italian National Evaluation Institute $\left(\operatorname{INVALSI}{ }^{20}\right)$ to the entire student population of $5^{\text {th }}$ (end of primary school) and $6^{\text {th }}$ graders (lower secondary school), consisting of approximately 500,000 students per grade (INVALSI, 2011). We "link" the survey administered in 2010 to $5^{\text {th }}$ graders to the survey administered in 2011 to $6^{\text {th }}$ graders, following children born in 1999.

Tests cover the domains of reading and mathematics, and were designed following the experience of international assessments. Students are asked to fill a questionnaire recording personal information, including family composition and home possessions, while school boards provide information on parental background. School teachers are normally in charge of test administration; however, in order to control for cheating, a random sample of classes (of about $30,000-40,000$ students) take the tests under the supervision of personnel external to the school. This sample represents a benchmark to evaluate performance scores of the general population. Sample mean scores are generally smaller than population values; the differential is interpreted as evidence of cheating (Quintano et al., 2009). Due to its better quality, our empirical analyses will be based on this sample data.

Performance is measured by the percentage of correct answers, varying between 0 and 100 . Scores are not vertically equated, so achievement is not comparable across grades. We employ two measures of socioeconomic status. The first is the number of books at home, in line with contributions in the economics of education. ${ }^{21}$ The second is the standardized index ESCS (Index of Economic-Socio-Cultural Status) provided by the National Agency and derived from data on

\footnotetext{
${ }^{19}$ Incidentally, aside from our own work (previous version in ...), De Simone (2013) is the only other contribution in the literature that we are aware of using pseudo-panel modeling to study achievement inequalities. As shown by the simulation exercises described in the Appendix, however, TIMSS does not have a sufficient sample size to ensure reliable results. Our empirical work also differs from De Simone (2013) in the choice of explanatory variables and identification strategy.

${ }^{20}$ Istituto Nazionale per la Valutazione del Sistema educativo di Istruzione e formazione.

${ }^{21}$ Children are asked to select a picture depicting a variable number of shelves with books.
} 
home possessions, parental education and occupation. ${ }^{22} \mathrm{We}$ also investigate gender, immigrant background and territorial differentials (according to macro-areas: North-West, North-East, Centre, South, Islands). All variables are summarized in Table 1.

Table 1. Descriptives. $5^{\text {th }}$ grade (2010 assessment) and $6^{\text {th }}$ grade (2011 assessment)

\begin{tabular}{|c|c|c|c|c|c|}
\hline \multicolumn{6}{|c|}{ DEPENDENT VARIABLES } \\
\hline VARIABLE & DESCRIPTION & MEAN $5^{\mathrm{TH}}$ & S.D. $5^{\mathrm{TH}}$ & MEAN $6^{\mathrm{TH}}$ & S.D. $6^{\mathrm{TH}}$ \\
\hline Score reading & Percentage correct answers reading test & 67 & 18 & 63 & 17 \\
\hline Score math & Percentage correct answers math test & 62 & 18 & 47 & 19 \\
\hline \multicolumn{6}{|c|}{ EXPLANATORY VARIABLES } \\
\hline VARIABLE & DESCRIPTION & MEAN $5^{\mathrm{TH}}$ & S.D. $5^{\mathrm{TH}}$ & MEAN $6^{\mathrm{TH}}$ & S.D. $6^{\mathrm{TH}}$ \\
\hline Female & Percentage females & 0.49 & & 0.49 & \\
\hline Books & $\mathrm{N}^{\circ}$ of books at home ${ }^{*}$ & 1.97 & 1.20 & 2.08 & 1.23 \\
\hline ESCS & Economic-Socio-Cultural Status Index & -0.02 & 1.00 & 0.03 & 1.00 \\
\hline Native & Native & 0.91 & & 0.90 & \\
\hline $2 \mathrm{G}$ & Second-generation migrant & 0.04 & & 0.04 & \\
\hline $1 \mathrm{G}$ & First-generation migrant & 0.05 & & 0.06 & \\
\hline North-West & Living in North-West & 0.24 & & 0.24 & \\
\hline North-East & Living in North-East & 0.17 & & 0.17 & \\
\hline Centre & Living in Centre & 0.18 & & 0.18 & \\
\hline South & Living in South & 0.24 & & 0.24 & \\
\hline Islands & Living in the Islands & 0.17 & & 0.17 & \\
\hline SAMPLE SIZE & READING-MATH & \multicolumn{2}{|c|}{$33997-33530$} & \multicolumn{2}{|c|}{$37196-37183$} \\
\hline
\end{tabular}

* $0=0$-10 books; $1=11-25$ books; $2=26-100$ books; $3=101-200$ books; $4=>200$ books

NOTES. The percentage of natives, first and second-generation immigrants are computed over the entire sample. All other descriptives refer to natives and second-generation immigrants only. Standard deviations for binary variables are not reported.

\subsection{Empirical analysis on native children}

In this section, we run pseudo-panel models on native children. The inclusion of immigrant students is problematic because they experience grade repetition much more frequently than natives. As will be discussed in the next section, grade repetition at $t=1$ may represent a threat to consistent estimation. Yet, since less than $1 \%$ repeat the school year in primary school, this issue is almost irrelevant for native children. ${ }^{23}$

\footnotetext{
${ }^{22}$ This measure, drawn from the international survey PISA, is the first factor of a principal component analysis.

${ }^{23}$ Models are estimated on children of birth cohort 1999 (the regular birth cohort for grade 5 in 2010 and grade 6 in 2011). In addition to children repeating grades, we exclude children born in 2000 (approximately $9 \%$ of the sample). This exclusion might cause non-random sample selection, as children starting school at age 5 (before the regular age) instead of age 6, could be more mature than their peers or have higher innate ability. For this reason we carried out some robustness checks by including these children in the estimation, attributing to them either month of birth 12 (as if they were all born in December 1999), or month 13 (for those born in January 2000), month 14 (for those born in February 2000) and so on. Since we find only minor changes, these results are not shown.
} 
Our instrumental variable is the month of birth, as there is empirical evidence that younger children perform more poorly than their older peers (Lawlor et al. 2006; Crowford et al., 2013). The first identifying assumption, verified within CS1, is that the month of birth affects $y_{1}$. The second one is that the month of birth does not directly affect $y_{2}: E\left(Y_{2} \mid y_{1}, x, w\right)=E\left(Y_{2} \mid y_{1}, x\right)$; since this assumption cannot be evaluated without longitudinal data, it was tested on a different dataset. $^{24}$

In order to account for the hierarchical structure of the data, we employed the Huber-White sandwich estimator for clustered data. ${ }^{25}$ Results for both reading and math are summarized in Table 2. The first columns contain the estimates of cross-sectional model (6) for $y_{1}$; the second report the estimates of the cross-sectional model $y_{i 2}=\mu_{2}+\beta x_{i}+\varepsilon_{i 2}$; the third contain the estimates of dynamic model (7).

Looking at cross-sectional results, the effects of individual ascribed characteristics are substantial at both assessments. In line with the international literature, socioeconomic status emerges as a strong predictor of performance: the coefficients of both indexes - number of books at home and ESCS - are large and highly statistically significant. Consider the reading assessment in $5^{\text {th }}$ grade: a unit increase in the number of books (coded as: $0=0-10$ books; $1=11-25$ books; $2=$ 26-100 books; $3=101-200$ books; $4=>200$ books) yields an average increase of 2.4 points; a unit increase in ESCS yields an increase of 3.3 points. ${ }^{26}$ This implies that when comparing a child with the lowest category of number of books (0) and a low value of ESCS (-2) with a child with the highest category of number of books (4) and a high value of ESCS (+2), on average the latter

\footnotetext{
${ }^{24}$ This dataset was collected in 2010 within the project "Scacchi e Apprendimento della Matematica" - Chess and Math Learning (Argentin and Romano "Standing on the Shoulders of Chess Masters: Using RTCs to Evaluate the Effects of Including Chess in the Italian Primary School Curriculum", in Besharov D. (eds), Evaluating Education Reforms: Lessons from Around the Globe, Oxford University Press, forthcoming). It provides two repeated performance measures at the beginning and the end of third grade. We thank the authors for permission to use these data.

${ }^{25}$ We employed the STATA procedure "vce(cluster)" that allows for intragroup correlation. "vce(cluster)" affects the standard errors and variance-covariance matrix of the estimators but not the estimated coefficients.

${ }^{26}$ Despite being an ordinal variable, to simplify the exposition we treated the number of books as cardinal. This choice has no relevant consequence on the results.
} 
scores 22.8 points more than the former. Females perform better than males in reading and worse in mathematics. Territorial differentials are dramatic, in particular along the North-South divide. For example, other things being equal, at both grades 5 and 6 the average reading score in the Islands is more than 6 points lower than in the North-West. The achievement level in mathematics does not differ significantly between the South and the North in grade 5 (while it is much poorer in the Islands), but in grade 6 the divide appears to widen substantially.

We now turn to the interpretation of the results of pseudo-panel estimates. $\beta$ coefficients in the dynamic model measure the extent to which achievement growth between $t=1$ and $t=2$ differs across $x$-categories, when comparing two equally performing children at $t=1$. We observe substantive socioeconomic and gender effects in reading but not in math. As for reading, children from high socioeconomic background, already advantaged in grade 5, do better in grade 6 than previously equally performing children of lower backgrounds (this is evident from the coefficient of ESCS, while that of books at home is not significant). On the other hand, they do not do any better or worse in mathematics. Similar results hold for gender effects: girls improve relative to boys in reading, while their disadvantage in math does not develop further. The opposite finding holds for area effects: they are small in reading but very large in math. The most noticeable result is that, given $5^{\text {th }}$ grade achievement, $6^{\text {th }}$ graders living in the North largely outperform their Southern peers. On the other hand, children living in the North-East close the math achievement gap with the North-West and perform best given previous scores.

Goodness of fit (measured by R-squared) is quite low in all models. This result is hardly surprising for cross-sectional models: indeed, ascribed characteristics cannot explain a large portion of the variability, even in educational systems with large inequalities across children of different backgrounds. Also the R-squared of the dynamic model is low; adding predicted lagged scores does not yield a substantial increase in goodness of fit, because measurement error due to the substitution of true lagged performance with an estimated value is (very) large. 
Table 2. Estimates of cross-sectional and pseudo-panel data models. Native children.

\begin{tabular}{|c|c|c|c|c|c|c|}
\hline \multirow[b]{2}{*}{ Variables } & \multicolumn{3}{|c|}{ READING } & \multicolumn{3}{|c|}{ MATHEMATICS } \\
\hline & $\begin{array}{c}5^{\text {th }} \text { grade } \\
\text { cross-section }\end{array}$ & $\begin{array}{c}6^{\text {th }} \text { grade } \\
\text { cross-section }\end{array}$ & $\begin{array}{l}6^{\text {th }} \text { grade } \\
\text { dynamic }\end{array}$ & $\begin{array}{c}5^{\text {th }} \text { grade } \\
\text { cross-section }\end{array}$ & $\begin{array}{c}6^{\text {th }} \text { grade } \\
\text { cross-section }\end{array}$ & $\begin{array}{l}6^{\text {th }} \text { grade } \\
\text { dynamic }\end{array}$ \\
\hline Costant & $65.8 * * *$ & $58.7 * * *$ & $14.1^{*}$ & $61.5 * * *$ & $45.3 * * *$ & $-21.1 * * *$ \\
\hline Month $^{1}$ & $-0.3 * * *$ & & & $-0.3 * * *$ & & \\
\hline Books $^{2}$ & $2.4 * * *$ & $2.1 * * *$ & 0.5 & $2.2 * * *$ & $2.5 * * *$ & 0.1 \\
\hline ESCS & $3.3 * * *$ & $3.9 * * *$ & $1.6 * * *$ & $3.0 * * *$ & $3.7 * * *$ & 0.4 \\
\hline Female & $0.8 * *$ & $2.2 * * *$ & $1.7 * * *$ & $-3.1 * * *$ & $-3.8 * * *$ & -0.3 \\
\hline North East & -0.5 & -0.6 & -0.3 & $-1.3 *$ & 1.0 & $2.4 * * *$ \\
\hline Centre & $-2.6 * * *$ & $-1.4 * * *$ & 0.5 & $-2.2 * *$ & $-2.9 * * *$ & -0.4 \\
\hline South & $-3.6 * * *$ & $-2.5 * * *$ & 0.1 & -0.9 & $-5.2 * * *$ & $-4.0 * * *$ \\
\hline Islands & $-6.3 * * *$ & $-6.5 * * *$ & $-1.9 *$ & $-4.0 * * *$ & $-8.4 * * *$ & $-3.7 * * *$ \\
\hline$y_{1}$ & & & $0.70 * * *$ & & & $1.12 * * *$ \\
\hline $\mathrm{R}^{2}$ & 0.132 & 0.158 & 0.160 & 0.091 & 0.156 & 0.160 \\
\hline RMSE & 15.86 & 14.89 & 14.87 & 17.15 & 17.03 & 16.99 \\
\hline sample size & 26616 & 29637 & 29637 & 27333 & 29636 & 29636 \\
\hline
\end{tabular}

$*$ p_value $<0.05 ; * *$ p-value $<0.01 ; * * *$ p-value $<0.005$

NOTES. The estimation has been performed only on children born in 1999.

1. January $=1, \ldots$ December $=12$

2. $0=0-10$ books; $1=11-25$ books; $2=26-100$ books; $3=101-200$ books; $4=>200$ books

Cluster robust standard errors (Huber-White sandwich estimator, run with STATA). Clusters defined by classes.

Let us now relate our findings with the theoretical arguments exposed in section 4, where we argued that cross-sectional regression coefficients are not fully informative on the development of inequalities between the two assessments. Consider cross-sectional estimates at grades 5 and 6 , and take their difference for each explanatory variable. These differences deviate from the corresponding dynamic coefficients - as shown by (5), they coincide only if $\omega=1$ and $\theta=0$, and in this case the lagged score coefficient in (3) is $\gamma=1$. Distances are larger for reading, as $\hat{\gamma}$ deviates more from 1 in the reading than in the math equation.

Let us look at the results for reading. If we were to interpret the development of territorial inequality between the North-West and the Islands from cross-sectional coefficients (-6.3 in grade 5, -6.5 in grade 6), we would conclude that it has hardly changed. Instead, the corresponding coefficient in the dynamic model (-1.9) clearly indicates that the disadvantage of the children in the Islands has substantially widened between grades 5 and 6. Similarly, from the cross-sectional point estimates of the ESCS coefficient (3.3 in grade 5, 3.9 in grade 6) we would conclude in favor of a mildly increasing socioeconomic effect, whereas the ESCS coefficient estimate of the dynamic 
model (1.6) points to considerably increasing socioeconomic inequalities.

Dynamic regression coefficients measure achievement growth differentials across $x$-categories when comparing two equally performing children at $t=1$. Thus, pseudo-panel $\beta$ s capture the new inequalities developed between the two surveys that can be directly ascribed to each explanatory variable. It is worth noticing that if we were interested in evaluating the component due to preexisting performance gaps (see section 3), we would not be able to do so, because the effect of previous performance on achievement growth is unidentified without vertically equated scores.

\subsection{Children repeating grades: the problem}

In a typical panel data setting $y_{1}$ is the value of $y$ at calendar time $1, y_{2}$ is the value of $y$ at time 2 and so on. Instead, in educational surveys where children of specific grades are interviewed, $y_{1}$ represents performance score at a specific grade (here, $5^{\text {th }}$ grade) and $y_{2}$ the score at a later grade (here, $6^{\text {th }}$ grade). As a consequence, if some children are required to repeat a grade, there will be two $y$ values at this grade. This poses no particular problems with genuine panel data ${ }^{27}$, but the situation is more complex for pseudo-panel estimation.

Figure 2 may help to illustrate the problem. In the columns we indicate calendar time. Consider the $5^{\text {th }}$ grade assessment held at calendar time $T$ and the $6^{\text {th }}$ grade assessment held at $T+1$ : pupils participating in these surveys belong either to cohort $k$ (regulars) or to cohort $k-1$ (one year late). In the rows we describe possible paths. Rows 1-3 refer to children of birth cohort $k$ : with a regular career, failing grade 6 and failing grade 5. Rows 4-5 depict children of cohort $k-1$ repeating either grade 5 or grade 6 . To simplify the picture, we assume that children may fail only once ${ }^{28}$ and that no repetitions occur before grade $5 .^{29}$

\footnotetext{
${ }^{27}$ The issue would be whether to model $y_{2}$ as dependent on the first or the second $y_{1}$.

${ }^{28}$ Repeated failures account for a negligible share of children in our data.

${ }^{29}$ The INVALSI survey does not provide information on repetitions but only the year of birth; therefore we cannot distinguish between children repeating the current grade or previous grades. We assume that children of earlier birth cohorts in grade 5 are repeating grade 5; the reason is that grade 5 represents the transition point from primary school, in which emphasis on achievement is low, to secondary school, in which it is much higher.
} 
Figure 2. Birth cohorts and assessments

\begin{tabular}{|c|c|c|c|c|c|c|}
\hline$T-1$ & $T$ & $T+1$ & $T+2$ & Row & Fail & Cohort \\
\hline & $\frac{5 \text { regular }}{\text { (birth cohort } k \text { ) }}$ & $\frac{6 \text { regular }}{\text { (birth cohort } k \text { ) }}$ & $\begin{array}{c}7 \text { regular } \\
\text { (birth cohort } k \text { ) }\end{array}$ & 1 & - & $k$ \\
\hline & $\frac{5 \text { regular }}{\text { (birth cohort } k \text { ) }}$ & $\underset{\text { (birth cohort } k \text { ) }}{6 \text { regular }}$ & $\begin{array}{l}6 \text { one year late } \\
\text { (birth cohort } k \text { ) }\end{array}$ & 2 & $\begin{array}{c}\text { Grade } \\
6\end{array}$ & $k$ \\
\hline & $\frac{5 \text { regular }}{\text { (birth cohort } k \text { ) }}$ & $\begin{array}{l}5 \text { one year late } \\
\text { (birth cohort } k \text { ) }\end{array}$ & $\frac{6 \text { one year late }}{\text { (birth cohort } k)}$ & 3 & $\begin{array}{c}\text { Grade } \\
5\end{array}$ & $k$ \\
\hline $\begin{array}{c}5 \text { regular } \\
\text { (birth cohort } k-1 \text { ) }\end{array}$ & $\begin{array}{l}5 \text { one year late } \\
\text { (birth cohort } k-1 \text { ) }\end{array}$ & $\begin{array}{l}6 \text { one year late } \\
\text { (birth cohort } k-1 \text { ) }\end{array}$ & & 4 & $\begin{array}{c}\text { Grade } \\
5 \\
\end{array}$ & $k-1$ \\
\hline $\begin{array}{c}5 \text { regular } \\
\text { (birth cohort } k-1 \text { ) }\end{array}$ & $\begin{array}{c}6 \text { regular } \\
\text { (birth cohort } k-1 \text { ) }\end{array}$ & $\begin{array}{l}6 \text { one year late } \\
\text { (birth cohort } k-1 \text { ) }\end{array}$ & & 5 & $\begin{array}{c}\text { Grade } \\
6\end{array}$ & $k-1$ \\
\hline
\end{tabular}

Let us focus on children of birth cohort $k$ and assume that we are interested in first time pupils attend each grade (underlined). We now argue that if there are no children failing before grade 5 the estimates based on regular children (grey shadowed cells) are unbiased. Consider equation (6), the cross-sectional model for $y_{1}$. The relevant set for its estimation consists of pupils of cohort $k$ participating to the $5^{\text {th }}$ grade assessment for the first time at time $T$. These children are all observed.

Consider now the estimation of (7), the dynamic model for $y_{2}$. Children in rows 1 and 2 pose no problem, since they participate to the $6^{\text {th }}$ grade assessment for the first time at $T+1$. Children in row 3 (repeating grade 5), instead, participate at $T+2$; hence, they are excluded from the estimation. This exclusion is related to achievement at $t=1$, which is an explanatory variable in model (7); therefore, it does not have severe consequences on the estimates, because sample selection on independent variables inflates standard errors but does not lead to biased estimates. ${ }^{30}$

Could we include children of birth cohort $k-1$ repeating grades to replace the unobserved children in row 3 ? Children in row 4 (repeating grade 5) are homologous to children in row 3; however, children in row 5 (repeating grade 6) are homologous to children in row 2, which are

\footnotetext{
${ }^{30}$ Limiting the analysis to regular children would produce biased estimates if year failure also occurred before the grade attended at $t=1$. In this case children failing before this grade would be excluded from the estimation of the model for $y_{1}$, because at calendar time $T$ they would still be attending an earlier grade. Regular children would represent a positively selected sample on the dependent variable, leading to biased estimates of $E\left(y_{1}\right)$ and of the coefficients of (7).
} 
already included in the estimation. Since previous school history is not recorded, it is not possible to distinguish children of row 4 and row 5. Hence, we may either include or exclude both of them. While, as argued above, excluding them does not have severe consequences, including both of them amounts to duplicating some observations and would lead to biased estimates. This result is shown in the simulation exercise described in Appendix A (Table A6).

\subsection{Including children with an immigrant background}

The inclusion of immigrant background students in the analyses and the evaluation of ethnic educational inequalities is problematic. First-generation immigrants are often placed in earlier grades at arrival in Italy, and therefore our instrument, children's age, would be endogenous. Moreover, this population is subject to significant changes in the short run due to territorial mobility. Newly arrived immigrants are also likely to have severe language problems and might therefore be excluded from the assessment. For these reasons, we exclude first-generation immigrants from empirical analyses. ${ }^{31}$

Second-generation immigrants are less subject to population instability, have been entirely exposed to the Italian schooling system and usually enter school at the regular age. Therefore comparing their achievement to that of natives is meaningful. In Italy, however, poorly achieving children are often required to repeat a grade. The repetition probability increases over the schooling career for all students and it is generally much higher for children with an immigrant background. According to the INVALSI data, in $5^{\text {th }}$ grade (survey 2010) less than $1 \%$ of natives and around $6 \%$ of second-generation immigrants were older than the regular age, while in $6^{\text {th }}$ grade (survey 2011) the proportion was $5 \%$ for natives and $15 \%$ for immigrants.

As already pointed out, these figures do not allow distinguishing between current and previous repetitions. Consistently with the discussion of section 5.3, we assume that no repetitions occur

\footnotetext{
${ }^{31}$ We define first-generation immigrants as children born abroad to two foreign-born parent and second-generation immigrants children born in Italy to two foreign-born parents.
} 
before grade 5, and base our estimates on children born in 1999, i.e. children presumably not repeating grades. The results are shown in Appendix B.

Cross-sectional estimates indicate that in the reading assessment children of immigrant background perform worse than natives by 4-6 points and in grade 6 the advantage of immigrant girls over boys is significantly larger than among natives. As for mathematics, in grade 6 there are significant territorial differences. In the North and the Centre, immigrant boys perform worse than native boys by approximately 4 points in both assessments; instead, immigrant girls do only marginally worse than native girls in grade 6 . In the South and the Islands the immigrant-native performance gap is substantially smaller.

The estimates of the dynamic model reveal that, given achievement in grade 5 , in grade 6 immigrant girls do not differ significantly from native girls in reading, while they substantially improve in math. Instead, immigrant boys do worse than native males in reading and remain stable in math. On math scores we also observe interaction effects between immigrant status and area of residence: while among natives the North-South divide widens between grade 5 and 6 (see also Table 2), among second-generation immigrants we observe no relevant changes. Overall, these findings suggest that although second-generation immigrant students are on average lower performing than natives, their disadvantage is largely established by the end of primary school. There is no evidence of growing immigrant background inequality in lower secondary school for girls, whereas for boys inequality widens in reading skills but not in mathematics.

\section{Summary and conclusions}

In this article we discuss the estimation of dynamic models from repeated cross-sectional standardized learning surveys, with the aim to assess how inequalities related to ascribed individual characteristics develop over childhood. Drawing on Verbeek and Vella (2005), we propose an imputed regression strategy allowing to "link" two surveys; the basic idea is that lagged scores are replaced by predicted values derived from a regression on the previous cross-section. 
We show that - given our research question and with appropriate explanatory variables - this strategy delivers consistent estimates of the parameters of interest. Moreover, by explicitly addressing the issue of measurement error, imputed regression provides consistent estimates of the parameters of interest even with test scores imperfectly measuring achievement.

If repeatedly applied to different segments of the schooling career, the method allows to investigate how inequalities develop over the schooling life course in educational systems where longitudinal data are not available. In principle, by exploiting international surveys, we could analyze cross-country differences and examine the relationship between the development of inequalities and specific features of the educational systems. ${ }^{32}$ This would represent a significant contribution to the literature on the effect of institutions on achievement inequalities, moving the focus from a static to a dynamic perspective.

The main drawback, however, is that due to the substitution of true lagged scores with an estimate, standard errors are largely inflated. This result is shown in the simulation study described in Appendix A. The practical implication is that sizable samples are needed. This conclusion limits the applicability of the proposed strategy: to date, it would be difficult to exploit international assessments for cross-country comparisons, as these samples are usually not large enough. ${ }^{33}$

In our empirical application we apply the pseudo-panel method to the large-scale learning assessments on reading and math literacy, carried out by the Italian National Evaluation Agency in 2010 and 2011 on children attending grades 5 and 6. We evaluate how gender, socioeconomic, immigrant background and territorial inequalities develop at the transition between primary and lower secondary school. The empirical analysis reveals that gender and socioeconomic inequalities widen in reading literacy but remain stable in math. On the contrary, the North-South divide does not change in reading but severely increases in math: this result suggests that math teaching in

\footnotetext{
32 TIMSS could be particularly well suited for this purpose, as it administers tests to children of given birth cohorts at grades 4 and 8 .

${ }^{33}$ Additional instruments could help increasing the efficiency of the estimation, but as we have argued above, they are difficult to find with the information currently available. School characteristics at $t=1$ might represent valid instruments, but are not recorded at $t=2$.
} 
lower secondary school could be much less effective in the South and Islands. Immigrant background differentials are largely established at the end of primary school; with the exception of reading skills for boys, second-generation immigrants do not lose ground with respect to natives in grade 6 , and girls even catch up part of their disadvantage in math.

\section{References}

Ammermueller, A. (2007) PISA: What makes the difference? Explaining the gap in test scores between Finland and Germany, Empirical Economics, 33, 2, 263-287

Barbieri, G., Rossetti C. and Sestito P. (2010) The Determinants of Teacher Mobility. Evidence from a Panel of Italian Teachers. Banca d'Italia Working Paper 761

Betebenner, D.W. and Linn, R. (2010) Growth in student achievement: issues of measurement, longitudinal data analysis, and accountability, Working Paper of the Centre for K-12 Assessment \& Performance Management

Card, D. and Lemieux, T. (1996) Wage dispersion, returns to skill, and black-white wage differentials, Journal of Econometrics, 74, 319-361

Crawford, C., Dearden, L. and Greaves, E. (2013) When you are born matters. Evidence from England. The Institute of Fiscal Studies, Report R80, http://www.ifs.org.uk/comms/r80.pdf

Cunha, F., Heckman, J.J, Lochner, L. and Masterov, D.V. (2006) Interpreting the evidence on life cycle skill formation, in Handbook of the Economics of Education (eds E. Hanushek and F. Welch), Chapter 12, pp. 697-812. Amsterdam: North Holland.

Deaton, A. (1985) Panel data from time series of cross-sections, Journal of Econometrics, 30, 109126.

De Simone, G. (2013) Render into primary the things which are primary's. Inherited and fresh learning divides in Italian lower secondary education, Economics of Education Review, 35, 12-23.

Fuchs, T. and Woessmann, L. (2007) What accounts for international differences in student performance? A re-examination using PISA data, Empirical Economics, 32, 2, 433-464

Fuller, W.A. and Hidiroglou, M.A. (1978) Regression estimation after correcting for attenuation, Journal of the American Statistical Association, 73, 99-104

Goldstein H. (2010) Multilevel Statistical Models, $4^{\text {th }}$ edition, John Wiley and Sons.

Goodman, A., Sibieta, L. and Washbrook, E. (2009) Inequalities in educational outcomes among children aged 3 to 16. Final report for the National Equality Panel, UK

Hanushek, E.A. and Woessmann, L. (2006) Does educational tracking affect performance and inequality? Differences-in-differences across countries, Economic Journal, 116, C63-C76.

INVALSI (2012) Le prove INVALSI 2011. Rapporto tecnico sulle caratteristiche delle prove INVALSI 2011. Rome: INVALSI. (Available from http://www.invalsi.it/areadati/SNV/1011/Rapporto_tecnico_prove_invalsi_2011.pdf).

Jerrim, J. and Choi, A. (2013) The mathematics skills of school children: how does England compare to the high performing East Asian jurisdictions? Working Paper of the Barcelona Institute of Economics 2013/12 
Jerrim, J. and Vignoles, A. (2012) Social Mobility, regression to the mean and the cognitive development of high ability children from disadvantaged homes, Journal of the Royal Statistical Society: Series A (Statistics in Society). doi: 10.1111/j.1467-985X.2012.01072.x.

Lawlor, D.A., Clark, H., Ronalds, J. and Leon, D.A. (2006) Season of birth and childhood intelligence: findings from the Aberdeen Children of the 1950s cohort study. British Journal of Educational Psychology 76(3), 481-499

Moffitt, R. (1993) Identification and estimation of dynamic models with a time series of repeated cross-sections, Journal of Econometrics, 59, 99-123

Mullis, I.V.S., Martin, M.O., Foy, P. and Arora, A. (2012) TIMSS 2011 International Results in Mathematics. Chestnut Hill, MA: TIMSS \& PIRLS International Study Center, Boston College.

Mullis, I.V.S., Martin, M.O., Foy, P. and Drucker, K.T. (2012). PIRLS 2011 International Results in reading. Chestnut Hill, MA: TIMSS \& PIRLS International Study Center, Boston College.

OECD (2010a) PISA 2009 results: what students know and can do. Student performance in reading, mathematics and science, Volume I. (Available from http://dx.doi.org/10.1787/9789264091450-en)

OECD (2010b) PISA 2009 results: overcoming social background. Equity in learning opportunities and outcomes. Volume II. (Available from http://dx.doi.org/10.1787/9789264091504-en).

Quintano, C., Castellano, R. and Longobardi, S. (2009) A Fuzzy Clustering Approach to Improve the Accuracy of Italian Student Data. An Experimental Procedure to Correct the Impact of Outliers on Assessment Test Scores. Statistica \& Applicazioni 7,149-171.

Schuetz, G., Ursprung, H.W. and Woessman, L. (2008) Education policy and equality of opportunity, Kyklos, 61(2), 279-308

Singer, J.D. and Willett, J.B. (2003) Applied longitudinal data analysis. Modelling change and event occurrence. New York: Oxford University Press.

Verbeek, M. and Vella, F. (2005) Estimating dynamic models from repeated cross-sections, Journal of Econometrics, 127, 83-102 


\section{Appendix A. Simulation study}

In an attempt to assess the practical relevance of the imputed regression strategy in educational achievement surveys, we run a simulation study to: (a) explore the behavior of the estimates obtained with imputed regression, as the sample size and predictive power of the instrument $w$ change; (b) compare the strategies: individual matching, cell mean regression and imputed regression; (c) assess the consequences of excluding school effects with longitudinal and imputed regression; (d) evaluate the imputed regression strategy when children repeating grades are included in the model.

The basic structure of the simulation design is the following. For each replication, we first generate explanatory variables as discrete uniform random variables (SES varies between 1 and 5, Month of birth between 1 and 12, Sex is a dummy variable and Area varies between 1 and 5). The error terms at $t=1$ and $t=2$ are distributed as independent normal random variables. We then generate two independent draws of $y_{1}$ according to model (2): the first represents the (unobserved) lagged achievement at $t=1$ of the children observed in CS2, the second is the achievement of children observed in CS1. At last, we simulate values of $y_{2}$ given lagged achievement, according to model (3).

When not stated differently, sample size is 30000 . We run 1000 replications, and then compute the average value of the estimates and two statistics related to standard errors: the standard deviation of regression coefficient estimates across replications (se.1), and the mean value of the resulting standard error estimates within each replication (se.2).

\section{(a) Imputed regression: varying sample size and predictive power of the instrument}

In section 4.1 we showed that the imputed regression strategy yields unbiased estimates of regression coefficients, but standard errors are inflated with respect to the estimation on genuine panel data, because the error term incorporates measurement error due to the substitution of true lagged scores with an estimate. In an attempt to assess the practical relevance of the imputed 
regression strategy in educational achievement surveys, we run a simulation exercise to explore the behavior of the estimates with changing sample size and predictive power of the instrument $w$. The column representing our case-study is grey shadowed.

Parameters are set approximately at the estimated values in our empirical analysis. ${ }^{34} \mathrm{We}$ consider two alternative sample sizes: 5000 (a typical size in the international assessments TIMSS) and 30000 (the sample size in the Italian survey). Results are summarized in Table A1. True values of parameters are in column one. In the other columns we find results. The column representing our case-study is grey shadowed.

Table A1. Imputed regression. Varying sample size and coefficient of the month of birth.

\begin{tabular}{|c|c|c|c|c|c|c|c|}
\hline & $\begin{array}{c}\text { TRUE } \\
\text { VALUE } \\
\end{array}$ & $\begin{array}{c}\mathrm{N}=30000 \\
\beta_{\text {month }}=-0.1\end{array}$ & $\begin{array}{c}\mathrm{N}=5000 \\
\beta_{\text {month }}=-0.1\end{array}$ & $\begin{array}{c}\mathrm{N}=30000 \\
\beta_{\text {month }}=-0.3\end{array}$ & $\begin{array}{c}\mathrm{N}=5000 \\
\beta_{\text {month }}=-0.3\end{array}$ & $\begin{array}{c}\mathrm{N}=30000 \\
\beta_{\text {month }}=-0.5\end{array}$ & $\begin{array}{c}\mathrm{N}=5000 \\
\beta_{\text {month }}=-0.5\end{array}$ \\
\hline SES & 2 & $\begin{array}{c}1.79 \\
(1.80,1.21) \\
\end{array}$ & $\begin{array}{c}1.96 \\
(32.1,4.9)\end{array}$ & $\begin{array}{c}1.99 \\
(0.45,0.37)\end{array}$ & $\begin{array}{c}1.85 \\
(1.23,0.95)\end{array}$ & $\begin{array}{c}1.99 \\
(0.27,0.23)\end{array}$ & $\begin{array}{c}1.96 \\
(0.68,0.58)\end{array}$ \\
\hline Sex & 2 & $\begin{array}{c}1.85 \\
(1.35,0.92)\end{array}$ & $\begin{array}{c}2.16 \\
(35.1,5.2)\end{array}$ & $\begin{array}{c}1.99 \\
(0.39,0.34)\end{array}$ & $\begin{array}{c}1.88 \\
(1.11,0.85)\end{array}$ & $\begin{array}{c}1.98 \\
(0.31,0.25)\end{array}$ & $\begin{array}{c}1.97 \\
(0.74,0.63)\end{array}$ \\
\hline Area & 2 & $\begin{array}{c}-1.90 \\
(0.90,0.61)\end{array}$ & $\begin{array}{c}-1.81 \\
(29.7,4.8)\end{array}$ & $\begin{array}{c}-2.00 \\
(0.23,0.20)\end{array}$ & $\begin{array}{c}-1.93 \\
(0.63,0.50)\end{array}$ & $\begin{array}{c}-1.99 \\
(0.16,0.13)\end{array}$ & $\begin{array}{c}-1.99 \\
(0.37,0.32)\end{array}$ \\
\hline$y 1$ & 0.7 & $\begin{array}{c}0.75 \\
(0.45,0.30)\end{array}$ & $\begin{array}{c}0.78 \\
(15.2,2.4)\end{array}$ & $\begin{array}{c}0.70 \\
(0.11,0.09)\end{array}$ & $\begin{array}{c}0.74 \\
(0.30,0.23) \\
\end{array}$ & $\begin{array}{c}0.70 \\
(0.07,0.06) \\
\end{array}$ & $\begin{array}{c}0.71 \\
(0.16,0.14)\end{array}$ \\
\hline Const & 20 & $\begin{array}{c}17.44 \\
(22.20,14.90)\end{array}$ & $\begin{array}{c}15.68 \\
(741.8,119.8)\end{array}$ & $\begin{array}{c}19.86 \\
(5.26,4.43)\end{array}$ & $\begin{array}{c}18.21 \\
(14.52,11.28)\end{array}$ & $\begin{array}{c}19.76 \\
(3.19,2.59) \\
\end{array}$ & $\begin{array}{c}19.57 \\
(7.65,6.48)\end{array}$ \\
\hline RMSE & & 16.41 & 16.40 & 16.41 & 16.42 & 16.41 & 16.41 \\
\hline $\mathrm{R} 2$ & & 0.21 & 0.21 & 0.21 & 0.22 & 0.22 & 0.22 \\
\hline
\end{tabular}

NOTES. Models generating data:

$y_{1}=50-\beta_{\text {month }} w+4 S E S+3$ sex -2 area $+\varepsilon_{1} ; y_{2}=20+0.7 y_{1}+2 S E S+2$ sex -2 area $+\varepsilon_{2}$ $\sigma\left(\varepsilon_{1}\right)=16, \sigma\left(\varepsilon_{2}\right)=12$

Range of explanatory variables: month of birth (1-12); SES(1-5); sex(0-1); area(1-5)

Average over 1000 replications' estimates.

In parenthesis: (st. dev of estimates over replications, mean se. of the estimates).

On average, the regression coefficient estimates are very similar to true parameters. Standard errors are generally large, in particular for small $n$ and coefficient of the month of birth. As these parameters increase, the estimates become more precise. ${ }^{35}$ Our major conclusion is that in order to

\footnotetext{
${ }^{34}$ The standard deviation of the error term in (3) cannot be estimated with pseudo-panel, so we have to guess a reasonable value for it. Since model (3) is conditional on previous performance, the error term variability is likely to be smaller than in (2). In the empirical analysis the estimate of the coefficient of $w$ is -0.3 ; in the simulation we let it vary between -0.1 and -0.5 .

${ }^{35}$ Se. 1 always exceeds se. 2 (although the differences are relatively small, in particular for large samples and predictive power of $w$ ). The reason is that the estimates of regression coefficients of $y_{2}$ are based on predicted values of $y_{1}$; the
} 
obtain reliable estimates large samples and good instruments are needed. With 5000 individuals, a typical country-level sample size in international assessment, the estimates are unstable, and can be totally unreliable with a very poor instrument. Instead, with a sample of 30000 students the results are satisfactory.

\section{(b) Individual matching, cell mean regression and imputed regression}

In this exercise we compare the estimates obtained with different estimation methods: individual matching, cell regression and imputed regression. Individual matching is performed by substituting true $y_{1}$ with a random value drawn from the same distribution given explanatory variables. For cell mean regression, we define cells according to the discrete values of all explanatory variables $(600 \text { cells })^{36}$. Since sample size is 30000 and the explanatory variables are independent uniforms, each cell has approximately 50 units. Results are summarized in Table A2.

Table A2. Comparison of alternative estimation strategies. Individual matching, cell mean regression, and imputed regression.

\begin{tabular}{|l|c|c|c|c|c|c|}
\hline & $\begin{array}{c}\text { TRUE } \\
\text { VALUE }\end{array}$ & $\begin{array}{c}\text { Individual } \\
\text { matching (1) }\end{array}$ & $\begin{array}{c}\text { Cell matching (1) } \\
600 \text { cells }\end{array}$ & $\begin{array}{c}\text { Cell matching (2) } \\
600 \text { cells }\end{array}$ & $\begin{array}{c}\text { Cell matching (3) } \\
600 \text { cells }\end{array}$ & $\begin{array}{c}\text { Imputed } \\
\text { regression (1) }\end{array}$ \\
\hline SES & 2 & $\begin{array}{c}4.79 \\
(0.07 .0 .07)\end{array}$ & $\begin{array}{c}4.33 \\
(0.17 .0 .17)\end{array}$ & $\begin{array}{c}2.83 \\
(0.13,0.13)\end{array}$ & $\begin{array}{c}2.26 \\
(0.10,0.10)\end{array}$ & $\begin{array}{c}1.99 \\
(0.45 .0 .37)\end{array}$ \\
\hline Sex & 2 & 4.08 & 3.75 & 2.62 & 2.21 & 1.99 \\
& & $(0.19 .0 .19)$ & $(0.24 .0 .23)$ & $(0.22,0.23)$ & $(0.22,0.23)$ & $(0.39 .0 .34)$ \\
\hline Area & -2 & -3.40 & -3.16 & -2.42 & -2.13 & -2.00 \\
& & $(0.07 .0 .07)$ & $(0.11 .0 .11)$ & $(0.09,0.09)$ & $(0.08,0.09)$ & $(0.23 .0 .20)$ \\
\hline$y 1$ & 0.7 & 0.00 & 0.12 & 0.49 & 0.63 & 0.70 \\
& & $(0.01 .0 .01)$ & $(0.04 .0 .04)$ & $(0.03,0.03)$ & $(0.02,0.02)$ & $(0.11 .0 .09)$ \\
\hline Const & 20 & 53.50 & 47.95 & 29.10 & 22.49 & 19.86 \\
& & $(0.41 .0 .42)$ & $(1.91 .1 .94)$ & $(1.19,1.20)$ & $(0.67,0.69)$ & $(5.26 .4 .43)$ \\
\hline RMSE & & 16.43 & 2.43 & 2.69 & 2.78 & 16.41 \\
\hline R2 & & 0.21 & 0.93 & 0.92 & 0.93 & 0.21 \\
\hline
\end{tabular}

NOTES. Models generating data:

$y_{1}=50-\beta_{\text {month }} w+4 S E S+3$ sex -2 area $+\varepsilon_{1} ; y_{2}=20+0.7 y_{1}+2 S E S+2$ sex -2 area $+\varepsilon_{2}$

$\sigma\left(\varepsilon_{1}\right)=16, \sigma\left(\varepsilon_{2}\right)=12$. Sample size $=30000$.

Values of explanatory variables: month of birth (1-12); SES(1-5); sex(0-1); area(1-5)

Average over 1000 replications' estimates.

In parenthesis: (st. dev of estimates over replications, mean se. of the estimates).

(1) $\beta_{\text {month }}=-0.3$; (2) $\beta_{\text {month }}=-1$; (3) $\beta_{\text {month }}=-2$

latter vary across replications, as also CS1 is a random sample. Se.1 incorporates this source of variability while within regression estimates of standard errors neglect it, because they are conditional on $\hat{y}_{1}$.

3612 (values of month of birth)*5 (values of SES)*2 (values of Sex)*5 (values of Area) $=600$ cells. 
In the first column we report the true values employed for data generation. The second column refers to individual matching: the estimate of the coefficient of lagged performance is nearly 0 and the effects of the other explanatory variables are strongly overestimated. In the last column we report the results of imputed regression already shown in Table A1. The three middle columns refer to cell mean regression. We allow the coefficient of the instrument (month of birth) to increase from -0.3 (the estimated value in our empirical application) to -2 . The magnitude of the bias diminishes as this coefficient increases in absolute value, but it is still noticeable even with a large sample and very high predictive power of the instrument.

In Table A3 we show the results of simulations aimed at evaluating the behavior of individual matching and cell mean regression with Fuller's correction for measurement error on lagged scores. This method requires an estimate of the reliability, i.e. the squared correlation between the observed explanatory variable (affected by measurement error) and its true counterpart. This quantity can be estimated by $\left(1-\frac{\widehat{v} \widehat{a r}\left(\varepsilon_{1}\right)}{v \widehat{a r}\left(y_{1}\right)}\right)$. Despite measurement error does not meet CEV conditions, Fuller's method works well in terms of bias: average values of the estimates are close to real values. Standard errors, however, are considerably larger than those obtained with imputed regression. 
Table A3. Comparison of alternative estimation strategies: individual matching and cell mean regression, with and without Fuller's correction

\begin{tabular}{|l|c|c|c|c|c|}
\hline & $\begin{array}{c}\text { True } \\
\text { value }\end{array}$ & $\begin{array}{c}\text { Individual matching } \\
\text { (no correction) }\end{array}$ & $\begin{array}{c}\text { Individual matching } \\
\text { (Fuller correction) }\end{array}$ & $\begin{array}{c}\text { Cell matching } \\
600 \text { cells } \\
\text { (no correction) }\end{array}$ & $\begin{array}{c}\text { Cell matching } \\
600 \text { cells } \\
\text { (Fuller correction) }\end{array}$ \\
\hline SES & 2 & $\begin{array}{c}4.79 \\
(0.07,0.07)\end{array}$ & $\begin{array}{c}4.25 \\
(1.14,1.12)\end{array}$ & $\begin{array}{c}4.33 \\
(0.17,0.17)\end{array}$ \\
\hline Sex & 2 & 4.08 & 3.68 & 3.75 & $(1.68,0.98)$ \\
& & $(0.19,0.19)$ & $(0.88,0.86)$ & $(0.24,0.23)$ & $(1.28,0.76)$ \\
\hline Area & -2 & -3.40 & -3.14 & -3.16 & -1.93 \\
& & $(0.07,0.07)$ & $(0.58,0.56)$ & $0.11,0.11)$ & $(0.84,0.50)$ \\
\hline$y 1$ & 0.7 & 0.00 & 0.14 & $(0.04,0.04)$ & $(0.41,0.24)$ \\
\hline Const & 20 & $(0.01,0.01)$ & $(0.28,0.28)$ & 47.95 & 18.25 \\
& & $(0.42,0.42)$ & $(13.70,13.41)$ & $(1.91,1.94)$ & $(19.83,11.75)$ \\
\hline RMSE & & 16.43 & 16.41 & 2.44 & 2.33 \\
\hline R2 & & 0.21 & 0.21 & 0.93 & 0.93 \\
\hline
\end{tabular}

NOTES. Models generating data:

$y_{1}=50-0.3$ month $+4 S E S+3$ sex -2 area $+\varepsilon_{1} ; y_{2}=20+0.7 y_{1}+2 S E S+2$ sex -2 area $+\varepsilon_{2}$

$\sigma\left(\varepsilon_{1}\right)=16, \sigma\left(\varepsilon_{2}\right)=12$. Sample size $=30000$.

Values of explanatory variables: month of birth (1-12); SES(1-5); sex(0-1); area(1-5)

Average over 1000 replications' estimates.

In parenthesis: (st. dev of estimates over replications, mean se. of the estimates).

Fuller's method run with STATA, procedure Eivreg.

\section{(c) School effects}

This simulation exercise is aimed at showing the behavior of pseudo-panel estimation when school-level effects operate. Our intent is to provide an empirical illustration of the theoretical arguments made in sections 4.3.1 and 4.3.2.

Like in our case-study, we consider the case where children change schools between the two surveys. We let school factors at $t=1$ be represented by random normal variables, mutually independent and independent of explanatory variables. Achievement at $t=1$ depends on innate ability (random term), SES and school factors at $t=1$. We consider two types of school factors at $t=2$, which we may conceive as school quality: (i) an independent random normal variable; (ii) a factor correlated to children's SES and previous achievement. Finally, achievement at $t=2$ depends on previous achievement, SES and school quality at $t=2$.

After data generation, we estimate longitudinal data regression models and the pseudo-panel model for $y_{2}$ given $y_{1}$, with and without school quality at $t=2$. The estimation is done by taking 
into account the hierarchical structure of the data using the cluster robust Huber-White sandwich estimator.

Results relative to the case of independent school factors are summarized in Table A4, while those with school quality correlated to SES and previous ability are reported in Table A.5. As predicted in section 4.3 , in the first scenario the estimates are always unbiased, while this is not the case in the second.

Table A4. Longitudinal and imputed regression with and without independent school variables

\begin{tabular}{|c|c|c|c|c|c|}
\hline & & \multicolumn{4}{|c|}{ Independent school factors } \\
\hline VALUE & $\begin{array}{c}\text { Longitudinal } \\
\text { model } \\
\text { with school } \\
\text { quality }\end{array}$ & $\begin{array}{c}\text { Longitudinal } \\
\text { model } \\
\text { without } \\
\text { school quality }\end{array}$ & $\begin{array}{c}\text { Imputed } \\
\text { regression } \\
\text { with school } \\
\text { quality }\end{array}$ & $\begin{array}{c}\text { Imputed } \\
\text { regression } \\
\text { without } \\
\text { school quality }\end{array}$ \\
\hline SES & 2 & $\begin{array}{c}2.01 \\
(0.06,0.05)\end{array}$ & $\begin{array}{c}2.00 \\
(0.06,0.06)\end{array}$ & $\begin{array}{c}1.99 \\
(0.39,0.34)\end{array}$ & $\begin{array}{c}1.98 \\
(0.41,0.36)\end{array}$ \\
\hline$y_{1}$ & 0.7 & $\begin{array}{c}0.70 \\
(0.01,0.01)\end{array}$ & $\begin{array}{c}0.70 \\
(0.1,0.1)\end{array}$ & $\begin{array}{c}0.70 \\
(0.10, .0 .09)\end{array}$ & $\begin{array}{c}0.70 \\
(0.10,0.09)\end{array}$ \\
\hline$S_{2}$ & 1 & $\begin{array}{c}1.00 \\
(0.01,0.01)\end{array}$ & - & $\begin{array}{c}1.00 \\
(0.02,0.02)\end{array}$ & - \\
\hline Cons & -10 & -9.99 & -9.97 & -10.10 & -10.22 \\
$(0.30,0.31)$ & $(0.40,0.40)$ & $(4.64,3.99)$ & $(4.85,4.31)$ \\
\hline RMSE & & 12.00 & 13.42 & 14.79 & 15.96 \\
\hline R2 & & 0.52 & 0.40 & 0.27 & 0.15 \\
\hline
\end{tabular}

NOTES. Average over 1000 replications' estimates. N children=30000; N schools=1500

In parenthesis: (standard deviation of the estimates over replications, mean standard error of the estimates).

Models generating data:

$y_{1}=50+4 S E S-0.3$ month $+u_{1}+\varepsilon_{1}$

$y_{2}=-10+0.7 y_{1}+2 S E S+0.5 s_{2}+\varepsilon_{2}$

$s_{2}$ random normal independent school-level variable, $\sigma\left(s_{2}\right)=6$

All random errors ( $u_{1}$ and $u_{2}$ school-level; $\varepsilon_{1}$ and $\varepsilon_{2}$ individual-level) normal, mutually uncorrelated and with

explanatory variables: $\sigma\left(u_{1}\right)=3, \sigma\left(u_{2}\right)=4, \sigma\left(\varepsilon_{1}\right)=12, \sigma\left(\varepsilon_{2}\right)=12$.

Range of explanatory variables: month of birth (1-12); SES (1-5)

Cluster robust standard errors (Huber-White estimator, run with STATA).

From Table A.5 we can see that the estimates relative to the longitudinal model with school quality are very similar to real values, whereas when we exclude school variables, the SES coefficient captures direct and indirect effects on performance at $t=2$ given $y_{1}$. Its estimate is approximately equal to 3 , both with longitudinal and imputed regression estimation. This correctly represents the overall effect of SES on $y_{2}$, as the direct effect is equal to 2 (the SES coefficient in the $y_{2}$ model), while the indirect effect through school quality at $t=2$ is equal to $2 * 0.5=1$ ( 2 is the 
coefficient of SES in the $s_{2}$ model and 0.5 is the coefficient of $s_{2}$ in the $y_{2}$ model). A similar case can be made for the coefficient of lagged achievement. Instead, as argued in section 4.3.2, when school quality is included in the pseudo-panel estimation, all estimates are severely biased.

Table A5. Longitudinal and imputed regression with and without dependent school variables

\begin{tabular}{|c|c|c|c|c|c|}
\hline & & \multicolumn{4}{|c|}{ School quality dependent on SES and previous achievement } \\
\hline VALUE & $\begin{array}{c}\text { Longitudinal } \\
\text { model } \\
\text { with school } \\
\text { quality }\end{array}$ & $\begin{array}{c}\text { Longitudinal } \\
\text { model } \\
\text { without } \\
\text { school quality }\end{array}$ & $\begin{array}{c}\text { Imputed } \\
\text { regression } \\
\text { with school } \\
\text { quality }\end{array}$ & $\begin{array}{c}\text { Imputed } \\
\text { regression } \\
\text { without } \\
\text { school quality }\end{array}$ \\
\hline SES & 2 & $\begin{array}{c}2.00 \\
(0.06,0.06)\end{array}$ & $\begin{array}{c}3.00 \\
(0.06,0.06)\end{array}$ & $\begin{array}{c}0.77 \\
(0.37,0.33)\end{array}$ & $\begin{array}{c}2.99 \\
(0.40,0.35)\end{array}$ \\
\hline$y_{1}$ & 0.7 & $\begin{array}{c}0.70 \\
(0.01,0.01)\end{array}$ & $\begin{array}{c}0.75 \\
(0.01,0.01)\end{array}$ & $\begin{array}{c}0.64 \\
(0.09,0.08)\end{array}$ & $\begin{array}{c}0.75 \\
(0.10,0.09)\end{array}$ \\
\hline$S_{2}$ & 0.5 & $\begin{array}{c}0.50 \\
(0.02,0.02)\end{array}$ & - & $\begin{array}{c}1.11 \\
(0.02,0.02)\end{array}$ & - \\
\hline Cons & -10 & -9.97 & -5.00 & -16.26 & -5.07 \\
$(0.36,0.36)$ & $(0.33,0.34)$ & $(4.39,3.94)$ & $(4.78,4.14)$ \\
\hline RMSE & & 12.00 & 12.17 & 14.57 & 15.30 \\
\hline R2 & & 0.53 & 0.52 & 0.31 & 0.24 \\
\hline
\end{tabular}

NOTES. Average over 1000 replications' estimates. N children=30000; N schools $=1500$

In parenthesis: (standard deviation of the estimates over replications, mean standard error of the estimates).

Models generating data:

$y_{1}=50+4 S E S-0.3$ month $+u_{1}+\varepsilon_{1}$

$y_{2}=-10+0.7 y_{1}+2 S E S+0.5 s_{2}+\varepsilon_{2}$

$s_{2}=10+2 S E S+0.1 y_{1}+u_{2}$

All random errors ( $u_{1}$ and $u_{2}$ school-level; $\varepsilon_{1}$ and $\varepsilon_{2}$ individual-level) normal, mutually uncorrelated and with explanatory variables: $\sigma\left(u_{1}\right)=3, \sigma\left(u_{2}\right)=4, \sigma\left(\varepsilon_{1}\right)=12, \sigma\left(\varepsilon_{2}\right)=12$.

Range of explanatory variables: month of birth (1-12); SES (1-5)

Cluster robust standard errors (Huber-White estimator, run with STATA).

\section{(d) Children repeating grades}

This simulation exercise has been carried out to evaluate imputed regression estimates with children repeating grades. We make children repeat grade 5 if their performance score is below a given threshold. The following year they move to grade 6 . The same rule applies to repetitions in grade 6 . No children fail before grade 5 .

Model (6) is estimated on regular children. As for dynamic model (7), we compare the behavior of the estimates when using only regular children and when including late children. We analyze two cases, with different shares of children failing the year. Since we introduced the issue of repeating grades when attempting to include immigrant children in the estimation, we add migrant 
status in the models. Given their poorer performance, low socioeconomic status and immigrant children are overrepresented among late children.

Results, shown in Table A6, confirm our theoretical expectations. We find no bias when analyzing only regular children, while we overestimate the effects when late children are included in the estimation.

Table A6. Imputed regression estimates with children repeating grades

\begin{tabular}{|c|c|c|c|c|c|}
\hline & \multirow{3}{*}{$\begin{array}{c}\text { TRUE } \\
\text { VALUE }\end{array}$} & \multicolumn{2}{|c|}{ Only regular children } & \multicolumn{2}{|c|}{ Regular and late children } \\
\hline & & \multicolumn{2}{|c|}{ Overall \% repeating grades } & \multicolumn{2}{|c|}{ Overall $\%$ repeating grades } \\
\hline & & $\begin{array}{c}0 \% \text { GRADE } 5 \\
10 \% \text { GRADE } 6\end{array}$ & $\begin{array}{ll}10 \% & \text { GRADE } 5 \\
20 \% & \text { GRADE } 6 \\
\end{array}$ & $\begin{array}{l}0 \% \text { GRADE } 5 \\
10 \% \text { GRADE } 6\end{array}$ & $\begin{array}{l}10 \% \text { GRADE } 5 \\
20 \% \text { GRADE } 6\end{array}$ \\
\hline$y_{1}$ & 0.7 & $\begin{array}{c}0.70 \\
(0.11,0.09) \\
\end{array}$ & $\begin{array}{c}0.71 \\
(0.12,0.10) \\
\end{array}$ & $\begin{array}{c}0.81 \\
(0.11,0.09) \\
\end{array}$ & $\begin{array}{c}0.75 \\
(0.11,0.09) \\
\end{array}$ \\
\hline SES & 2 & $\begin{array}{c}2.00 \\
(0.44,0.37) \\
\end{array}$ & $\begin{array}{c}1.97 \\
(0.47,0.40) \\
\end{array}$ & $\begin{array}{c}2.33 \\
(0.46,0.38) \\
\end{array}$ & $\begin{array}{c}2.30 \\
(0.46,0.37) \\
\end{array}$ \\
\hline mig & -3 & $\begin{array}{c}-2.99 \\
(0.51,0.44)\end{array}$ & $\begin{array}{c}-2.97 \\
(0.55,0.47)\end{array}$ & $\begin{array}{c}-3.43 \\
(0.54,0.44)\end{array}$ & $\begin{array}{c}-3.26 \\
(0.53,0.43)\end{array}$ \\
\hline Constant & 10 & $\begin{array}{c}9.93 \\
(5.25,4.43)\end{array}$ & $\begin{array}{c}9.63 \\
(5.62,4.70)\end{array}$ & $\begin{array}{c}0.53 \\
(5.44,4.52)\end{array}$ & $\begin{array}{c}3.31 \\
(5.44,4.33)\end{array}$ \\
\hline
\end{tabular}

NOTES. Models generating data:

$y_{1}=50-0.3$ month $+4 S E S+4 m i g+\varepsilon_{1} ; y_{2}=10+0.7 y_{1}+2 S E S+2$ sex $-3 m i g+\varepsilon_{2}$ $\sigma\left(\varepsilon_{1}\right)=16, \sigma\left(\varepsilon_{2}\right)=12$. Sample size $=30000$.

Values of explanatory variables: month of birth (1-12); migrant $(0,1) 20 \%$ migrants

Average over 1000 replications' estimates.

In parenthesis: (st. dev of estimates over replications, mean se. of the estimates). 


\section{Appendix B. Models with natives and second-generation immigrants}

Table B1. Estimates of cross-sectional and pseudo-panel data models (natives and second-generation immigrants)

\begin{tabular}{|c|c|c|c|c|c|c|}
\hline \multirow[b]{2}{*}{ Variables } & \multicolumn{3}{|c|}{ READING } & \multicolumn{3}{|c|}{ MATHEMATICS } \\
\hline & $\begin{array}{c}5^{\text {th }} \text { grade } \\
\text { cross-section }\end{array}$ & $\begin{array}{c}6^{\text {th }} \text { grade } \\
\text { cross-section }\end{array}$ & $\begin{array}{l}6^{\text {th }} \text { grade } \\
\text { dynamic }\end{array}$ & $\begin{array}{c}5^{\text {th }} \text { grade } \\
\text { cross-section }\end{array}$ & $\begin{array}{c}6^{\text {th }} \text { grade } \\
\text { cross-section }\end{array}$ & $\begin{array}{l}6^{\text {th }} \text { grade } \\
\text { dynamic }\end{array}$ \\
\hline Costant & $66.0 * * *$ & $58.8 * * *$ & $13.0 *$ & $61.7 * * *$ & $45.4 * * *$ & $-16.0 * *$ \\
\hline Month $^{1}$ & $-0.3 * * *$ & & & $-0.3 * * *$ & & \\
\hline $2 \mathrm{G}$ & $-6.2 * * *$ & $-6.6 * * *$ & $-2.2 *$ & $-4.5 * * *$ & $-4.2 * * *$ & \\
\hline Female & $0.7 * * *$ & $2.2 * * *$ & $1.7 * * *$ & $-3.2 * * *$ & $-3.7 * * *$ & -0.5 \\
\hline Female 2G & & $2.9^{*}$ & $2.9^{*}$ & & $2.6^{*}$ & $3.1 * *$ \\
\hline Books $^{2}$ & $2.3 * * *$ & $2.1^{* * * *}$ & 0.4 & $2.1 * * *$ & $2.4 * * *$ & 0.2 \\
\hline ESCS & $3.3 * * *$ & $3.9 * * *$ & $1.5 * * *$ & $3.0 * * *$ & $3.7 * * *$ & 0.5 \\
\hline North East & -0.7 & -0.6 & -0.1 & $-1.3^{*}$ & 0.9 & $2.4 * * *$ \\
\hline Centre & $-2.6 * * *$ & $-1.3 * * *$ & 0.5 & $-2.1 * *$ & $-2.8 * * *$ & -0.6 \\
\hline South & $-3.6^{* * * *}$ & $-2.5 * * *$ & 0.2 & -0.9 & $-5.1 * * *$ & $-4.1 * * *$ \\
\hline Islands & $-6.3 * * *$ & $-6.5 * * *$ & $-1.8 *$ & $-4.0 * * *$ & $-8.4 * * *$ & $-4.1 * * *$ \\
\hline South-Isl 2G & & & & & $3.6^{*}$ & $3.8 *$ \\
\hline$y_{1}$ & & & $0.718 * * *$ & & & $1.031 * * *$ \\
\hline $\mathrm{R}^{2}$ & 0.135 & 0.161 & 0.163 & 0.094 & 0.155 & 0.157 \\
\hline RMSE & 15.91 & 14.94 & 14.93 & 17.11 & 17.05 & 17.02 \\
\hline sample size & 27779 & 30882 & 30882 & 28542 & 30881 & 30881 \\
\hline
\end{tabular}

$*$ p_value $<0.05 ; * *$ p-value $<0.01 ; * * *$ p-value $<0.005$

NOTES. The estimation has been performed only on children born in 1999.

1. January $=1, \ldots$ December $=12$

2. $0=0-10$ books; $1=11-25$ books; $2=26-100$ books; $3=101-200$ books; $4=>200$ books

Cluster robust standard errors (Huber-White estimator, run with STATA). Clusters defined by classes.

Interactions effects are reported only when significant. 